\title{
Propuesta metodológica para la restitución de la planimetría de una arquitectura medieval desaparecida: la iglesia románica del monasterio de San Julián de Samos (Lugo)
}

\section{Methodological proposal in order to reconstruct the plans of a disappeared medieval architecture: the Romanesque church of St. Julian's Monastery at Samos (Lugo)}

\author{
Estefanía López Salas
}

Departamento de Composición. Universidad de A Coruña e-mail: estefania.Isalas@udc.es

\begin{abstract}
RESUMEN
El monasterio de San Julián de Samos (Lugo) es uno de los edificios religiosos más grandes de Galicia y también uno de los que goza de mayor antigüedad dentro del monacato español. El presente artículo se enmarca dentro de una investigación más amplia, en la que se analiza el largo proceso constructivo experimentado por dicho monumento, desde sus orígenes hasta la actualidad, con el fin de comprender la realidad de su arquitectura y valorar qué hay de auténtico y de nuevo en su fábrica. En este trabajo, presentamos el método desarrollado para llevar a cabo la reconstrucción gráfica del aspecto de este monasterio, en una de las primeras fases de su proceso evolutivo, la época bajomedieval.
\end{abstract}

Palabras clave: arquitectura medieval; documentación histórica; resto arquitectónico; proceso evolutivo; reconstrucción gráfica.

\begin{abstract}
St. Julian's Monastery at Samos (Lugo) is one of the largest religious buildings in Galicia and it is also one of the oldest Spanish monasteries. The present paper is part of a wider research, which intends to analyse the long constructive process undergone by this monument, from its origin to the present time, in order to understand the reality of its architecture and value what it is original and new. This work shows the methodology developed to undertake the graphic reconstruction of one of the earliest stages of this monastery, namely the late-medieval period.
\end{abstract}

Keywords: Medieval architecture; historical documentation; architectural remain; evolutionary process; graphic reconstruction. 


\section{I NTRODUCCI ÓN}

El presente artículo muestra el método desarrollado para llevar a cabo la reconstrucción gráfica de una de las primeras etapas del proceso creativo de la fábrica monacal de San Julián de Samos, la correspondiente al periodo bajomedieval. Este trabajo se enmarca dentro de una investigación más amplia, centrada en el análisis, de forma rigurosa y profunda, del dilatado proceso constructivo experimentado por dicho monasterio a lo largo del tiempo y que ha sido responsable de la imagen con la que hoy se muestra, gran palimpsesto de múltiples intervenciones, realizadas en diversas épocas, que dificultan su comprensión global.

El trabajo que aquí presentamos se ha desarrollado desde la postura de un arquitecto ante una pieza arquitectónica histórica, pero sin entrar en el campo específico de la arqueología. Con ello queremos señalar, desde un principio, que la metodología de análisis elaborada para el alcance del objetivo planteado, no sigue el camino habitual de la lectura estratigráfica como herramienta de documentación de los restos conservados, de estructura parcialmente no visible o muy modificada por actuaciones de época moderna y contemporánea.

Sin dejar de lado el conocimiento de la materialidad del edificio, se realiza un estudio paralelo, objetivo y racional de los objetos en sí mismos, apoyándonos en las referencias documentales existentes, en el análisis de obras tipológicamente similares y en la observación directa de todas y cada una de las piezas que, en el pasado, pudieron pertenecer al conjunto monacal románico.

En este proceso de trabajo nuestra herramienta principal es el dibujo y los medios de partida, los documentos históricos y la realidad arquitectónica conservada (su forma, sus medidas, sus materiales, su técnica, su decoración,...), fuentes de las que se pueden obtener datos para la documentación de una arquitectura histórica, igualmente válidos que los procedentes de un análisis estrictamente estratigráfico ${ }^{1}$.

\footnotetext{
1 "Cuando en un edificio es posible conocer y fechar, directa o indirectamente, muchas de sus partes (forma de ciertas estructuras, elementos arquitectónicos, recubrimientos), se puede decir que, incluso en ausencia de estratigrafía visible, es posible un análisis arqueológico, basado en su observación y en las discusiones objetivas sobre la construcción en sí misma". Mannoni, 1998, pp. 83-84.

Aunque no hemos seguido su metodología, el estudio presentado en este artículo puede relacionarse con lo que Mannoni denomina “análisis configuracional", aquel en el que, sin ser posible realizar un estudio estratigráfico completo, porque los revestimientos ocultan gran parte de la superficie muraria del conjunto analizado, se recurre al estudio tipológico y a los documentos escritos, como fuentes de datos para un análisis arqueológico no destructivo, igualmente válido, aunque con ciertas limitaciones. Utrero Agudo, 2010, p. 16.
}

Pero antes de abordar el objetivo planteado, en este apartado introductorio consideramos necesario relacionar aquellos trabajos que, con anterioridad, se ocuparon del estudio del monasterio de Samos en los siglos bajomedievales y, más concretamente, los que se preocuparon por conocer la producción arquitectónica en ese periodo, dentro de lo que se denomina arte románico.

A pesar de que el monasterio de Samos es uno de los monumentos mejor estudiados del monacato gallego, no son muchas las obras que se centraron en el periodo bajomedieval y, las que sí lo hicieron, en la mayoría de los casos no fueron concebidas como estudios específicos sobre los restos románicos aquí investigados ${ }^{2}$, sino como trabajos con un carácter global, dedicados al conocimiento del conjunto monacal desde sus primeros años hasta la actualidad.

Dentro de los que podemos llamar protagonistas del estado de la cuestión, fue Castro el que inició el estudio de la arquitectura medieval samonense, en una serie de artículos (1912). El siguiente paso fue dado por Durán (1947) con una obra de pequeña envergadura dedicada al estudio histórico-arqueológico del conjunto monacal, que comprende algunos apartados de análisis de los restos medievales que hoy permanecen.

La transcripción del conocido como Tumbo de Samos realizada por Lucas Álvarez (1986) representa un punto de inflexión en el conocimiento de diversos aspectos del monasterio entre los siglos VIII y XII, al ser la única fuente documental directa conservada de aquella época. Tras su publicación vieron la luz dos trabajos de Arias Cuenllas $(1981,1983)$ dedicados al estudio específico de este conjunto monacal desde sus orígenes hasta el siglo XII, que se completaron en su extensa monografía sobre la historia del monasterio publicada en 1992.

La producción bibliográfica continuó con las aportaciones de De la Portilla Costa (1978, 1984, 1988) que, sin embargo, mantenían el carácter global de los estudios anteriores.

Para encontrar obras que, de forma completa o en alguna de sus partes, contengan un estudio que atienda al conocimiento de los restos de la desaparecida iglesia románica de Samos, con mayor rigor, tenemos que esperar hasta fechas muy recientes.

\footnotetext{
${ }^{2}$ Los restos analizados en este trabajo pertenecen al periodo bajomedieval (siglos XII-XIII). Dejamos fuera de este estudio la llamada Capilla del Ciprés o del Salvador, una pieza arquitectónica prerrománica, construida a finales del siglo IX o principios del siglo X que, tanto por su posición, — ciertamente alejada del monasterio actual-, como por su datación, perteneció al conjunto monacal primitivo o altomedieval. Los trabajos publicados sobre esta obra superan considerablemente en número y grado de profundización a los que relacionamos sobre los restos románicos.
} 
Yzquierdo Perrín (2001), al ocuparse del arte medieval en el arciprestazgo de Samos, dedicó un apartado concreto a la catalogación y estudio de los elementos románicos conservados en el monasterio actual.

El siguiente avance en este campo vino de manos de Casal Chico quien, en su tesis de licenciatura, profundizó en el conocimiento histórico-artístico de los restos medievales del monasterio, si bien centrándose más en los correspondientes al periodo altomedieval, que en los propiamente románicos ${ }^{3}$.

Para terminar este breve recorrido por la cuestión historiográfica, tenemos que citar el último trabajo publicado sobre el monasterio de Samos que, bajo el título San Julián de Samos. Historia e arte nun mosteiro (2008), recoge una serie de artículos que, en algunos casos, se ocuparon del estudio de la arquitectura samonense en el periodo bajomedieval ${ }^{4}$.

\section{EL PROCESO DE RECONSTRUCCIÓN DEL ESPACIO MEDI EVAL PERDI DO: LAS FUENTES Y SU TRATAMI ENTO}

Del monasterio bajomedieval de Samos hoy en día sólo se conservan algunos restos correspondientes, en su mayor parte, a un templo románico desaparecido. De todos ellos, un primer grupo lo forman los elementos que no mantienen su aspecto original, porque sufrieron reformas en épocas posteriores; el segundo, aquellos que no están en su ubicación primitiva, pues fueron trasladados a distintos lugares, bien para seguir siendo utilizados cuando se derribó la iglesia románica o bien conservados como piezas independientes; y un tercer grupo los que no pertenecieron en un primer momento al templo bajomedieval, sino que son resultado de diferentes procesos de reforma que se llevaron a cabo en él en el transcurrir de los años. Sin embargo, la suma de todos esos vestigios y su estudio pormenorizado, es más que suficiente para constatar la anterior existencia de esa pieza arquitectónica, elemento fundamental en la configuración del conjunto monástico bajomedieval, y para poder hacer hipótesis de cómo pudo haber sido.

\footnotetext{
3 Carolina Casal solamente reconoció como resto románico la portada de la antigua iglesia de Samos, de la cual realizó un profundo análisis tipológico, más quedaron excluidos del estudio todo otro conjunto de elementos correspondientes al mismo periodo histórico-artístico. Casal Chico, 2002, Estudio histórico-artístico: los restos medievales del monasterio de San Julián de Samos (tesis de licenciatura inédita. Universidad de Santiago de Compostela), pp. 150-163 y 194.

${ }^{4}$ Así ocurre con los artículos de Rodríguez González, 2008, Folgar de la Calle, 2008 y López Calderón, 2008. Las dos últimas solamente atendieron a algunos aspectos de cómo fue el espacio románico en su última fase de existencia.
}

Al primer grupo pertenece el elemento más significativo, por ser el que ha sobrevivido al paso de los siglos en su posición original, factor clave para que lo tomemos como punto de partida en el estudio de la obra medieval. Se trata de lo que en el pasado fue el ángulo sur del templo románico ${ }^{5}$, a saber, parte de la fachada principal con la escalera de caracol que subía por el interior de una de las torres que poseía, y parte de la fachada sur con un contrafuerte y una portada sencilla, pero con elementos y características propias del arte románico, como las columnas que la flanquean por ambos lados, rematadas en capiteles de variada decoración y que sirven de apoyo a las arquivoltas de medio punto que cubren el vano (Figs. 1 y 2). En los sillares que conforman este esquinal todavía se pueden reconocer talladas distintas marcas de cantería $(\mathrm{P}, \Lambda, \mathrm{D}, \mathrm{CO}, \mathrm{F})$ que nos indican que en su construcción participaron varios canteros (Figs. 3, 4 y 5). El aspecto original de la portada fue modificado con la disposición de una pequeña bóveda de cañón con casetones, de estilo renacentista, que cubre el espacio de aproximación a ella. De igual modo, la observación de fotografías de la primera mitad del siglo XX, permite reconocer que la parte superior del hueco de la puerta fue restaurada, posiblemente en la segunda mitad de dicha centuria (Figs. 6 y 7).

Forman parte del segundo grupo los elementos de la primitiva iglesia románica que, cuando ésta fue derribada, en 1746, se trasladaron al nuevo templo, el que hoy existe, o bien se conservaron como piezas independientes: parte de las losas de piedra de su pavimento, la escalera interior de una de las torres que poseía, un fragmento de una línea de imposta ${ }^{6}$, algún capitel y un sarcófago ${ }^{7}$.

El tercer grupo lo constituyen aquellas piezas que fueron diseñadas para el templo románico, principalmente para adecuar su espacio interior a lo largo de diferentes procesos de reforma y que, una vez desaparecido este, se reutilizaron en el nuevo y en él se conservan actualmente. Se trata de varios altares, entre los que destacan, por permanecer casi totalmente completos, los de San Benito, la Virgen y Santa Gertrudis, los púlpitos y los órganos, todos ellos elaborados a lo largo del siglo XVII ${ }^{8}$.

\footnotetext{
5 Sobre los restos de la antigua iglesia románica de Samos han estudiado: Castro, 1912, pp. 114-116, 192-195; Durán, 1947, pp. 31-39; De la Portilla Costa, 1978, pp. 20-21; De la Portilla Costa, 1984, p. 19; Yzquierdo Perrín, 2001, 5861; Casal Chico, 2002, citado supra en n. 3: pp. 150-163 y 194.

${ }^{6}$ Rodríguez González, 2008, p. 49.

7 Sobre el sarcófago del siglo XII: De la Portilla Costa, 1978, pp. 22-23; Arias Cuenllas, 1992, p. 142; Yzquierdo Perrín, 2001, p. 59.

${ }^{8}$ Castro, 1912, pp. 115-117, 168-170; Vila Jato, 1974-1975, pp. 141-146; De la Portilla Costa, 1978, pp. 32-39; Arias Cuenllas, 1992, pp. 224, 543; De la Portilla Costa, 2001, pp. 145-163; López Calderón, 2008, pp. 193-208.
} 


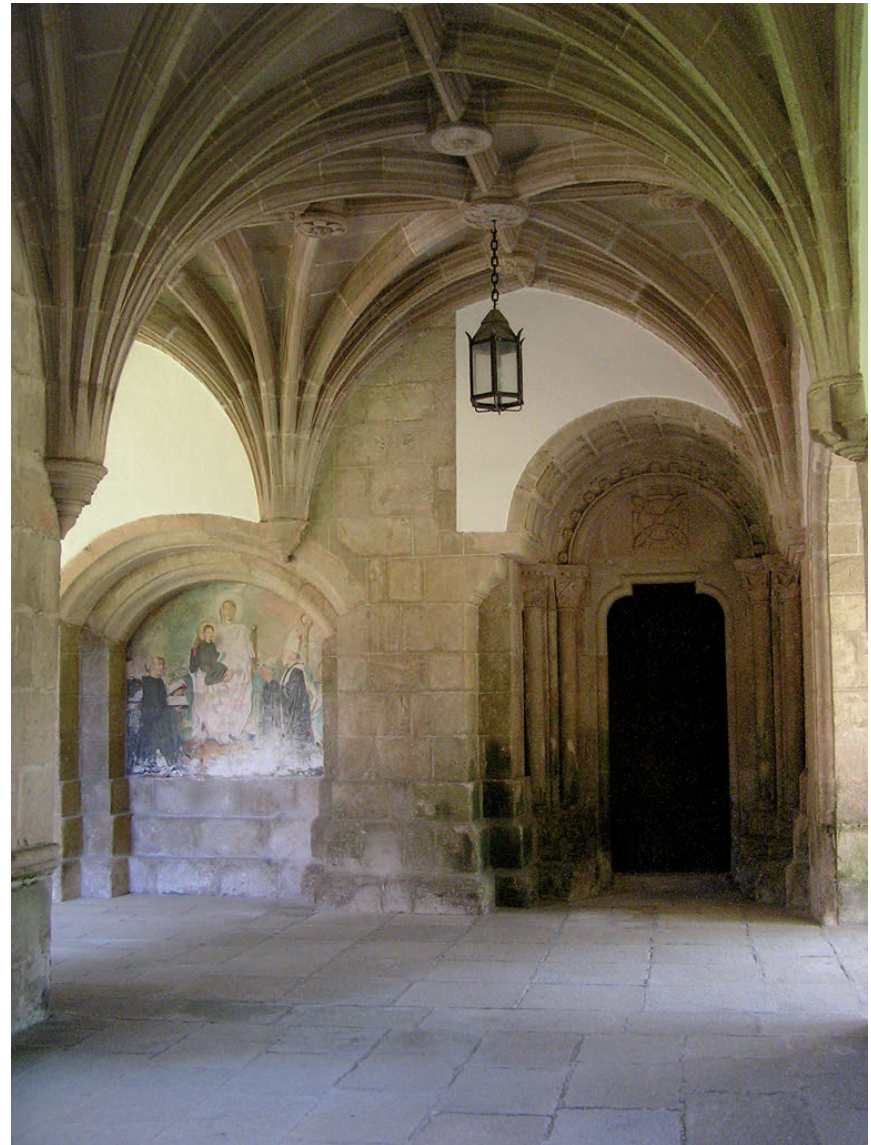

Figura 1. Portada y contrafuerte conservados del antiguo templo románico de Samos (Fotografía de la autora)

Pero no sólo los restos materiales citados, que iremos analizando poco a poco en las páginas posteriores, prueban que en la Baja Edad Media hubiera una verdadera iglesia románica en Samos. A nivel documental también consta su existencia. Hasta nuestros días ha llegado en el Tumbo de Samos una copia de la concordia celebrada en 1167 entre el abad y sus monjes ${ }^{9}$, en la cual se hace mención expresa de la intención de construir una iglesia. Para poner fin a las quejas que la comunidad había hecho por no tener lo necesario en cuanto a comida y ropa para cumplir con sus obligaciones, el obispo de Lugo, Juan, tras escuchar las explicaciones de ambas partes, puso fin al problema redactando una escritura de concordia, que recibió la aprobación tanto del abad como de los monjes. En este acuerdo tiene origen lo que se denominó la claustra, es decir, el reparto de la hacienda del monasterio entre el abad y la comunidad ${ }^{10}$. Entre las numerosas distribuciones que se hicieron y que han quedado reflejadas en ese documento, lo que nos interesa ahora es el reparto

\footnotetext{
${ }_{9}$ Escritura no 51 del Tumbo de Samos en Lucas Álvarez, 1986, pp. 149-152.

${ }_{10}$ Arias Cuenllas, 1992, p. 140.
}

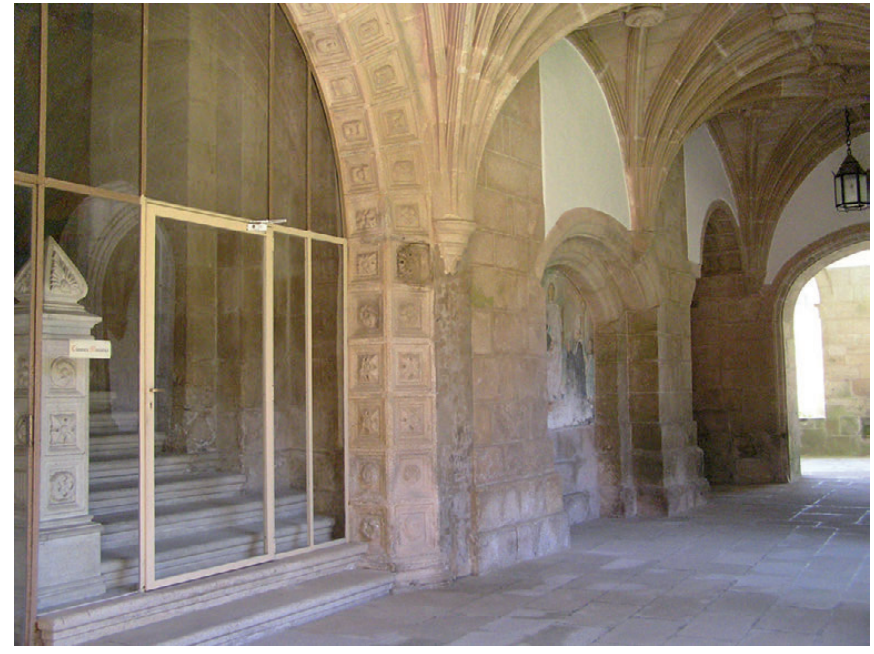

Figura 2. Ángulo suroeste conservado del antiguo templo románico de Samos (Fotografía de la autora)

de las donaciones ofrecidas al monasterio por los difuntos, de las cuales se especificaba que "la mitad será para el abad y la otra mitad la recogerá el camerario"11, el encargado de vestir a la comunidad, y añadía, "excepto cuando el abad inicie las obras de la iglesia”"12, momento en el que serían para el abad dos partes de las donaciones y la tercera para el monje camerario.

Sesenta y un años después, en 1228, e igualmente en una concordia por el reparto de los bienes entre el abad y los monjes, encontramos referencias a las obras de la iglesia, cuando al detallar la distribución de las donaciones de los fallecidos al monasterio, se fijaba que "se dividan en cuatro partes: una para el abad, otra para el sustento de los hermanos, la tercera para el monje camerario y la cuarta para la construcción de la iglesia", añadiendo "hasta que se finalice"13, lo cual hace suponer que estaba próximo su término. Con estos datos podemos afirmar que la construcción del templo románico se llevó a cabo aproximadamente entre 1167 y 1228, y gracias a las donaciones de los difuntos.

Aunque las referencias a cómo era la iglesia medieval son escasas, tenemos tres formas de llegar a la hipótesis de cómo pudo haber sido su planta. La primera es la que hemos denominado documental, es decir, la reunión y análisis de los textos que sobre ella han recogido

\footnotetext{
11 Ibidem, p. 141.

12 Lucas Álvarez, 1986, p. 150. La escritura de concordia dice: "Eorum etiam que pro defunctorum animabus monasterio data fuerint, medietas camerario, medietas detur abbati, excepto quando opus ecclesie fecerit abbas, tunc due partes abbati, tercia camerario detur; (...)".

${ }^{13}$ Castro, 1912, pp. 114-115; De la Portilla Costa, 1984, p. 19; Arias Cuenllas, 1992, p. 160; Yzquierdo Perrín, 2001, p. 59; Casal Chico, 2002, citado supra en n. 3: pp. 150-163.
} 


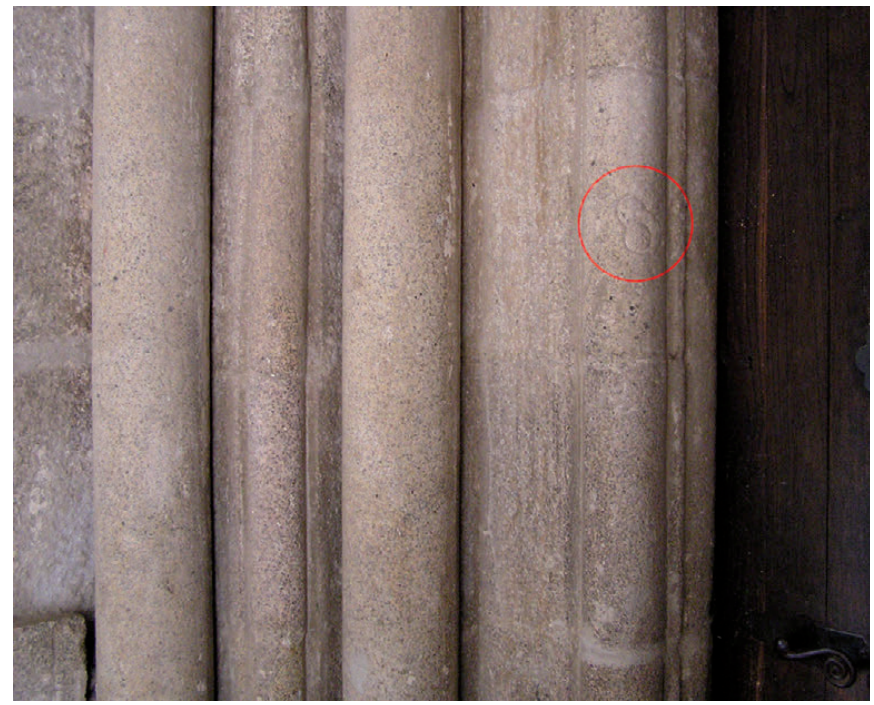

Figura 3. Marca de cantería (CO) tallada en una de las columnas del lado izquierdo de la portada románica (Fotografía de la autora)

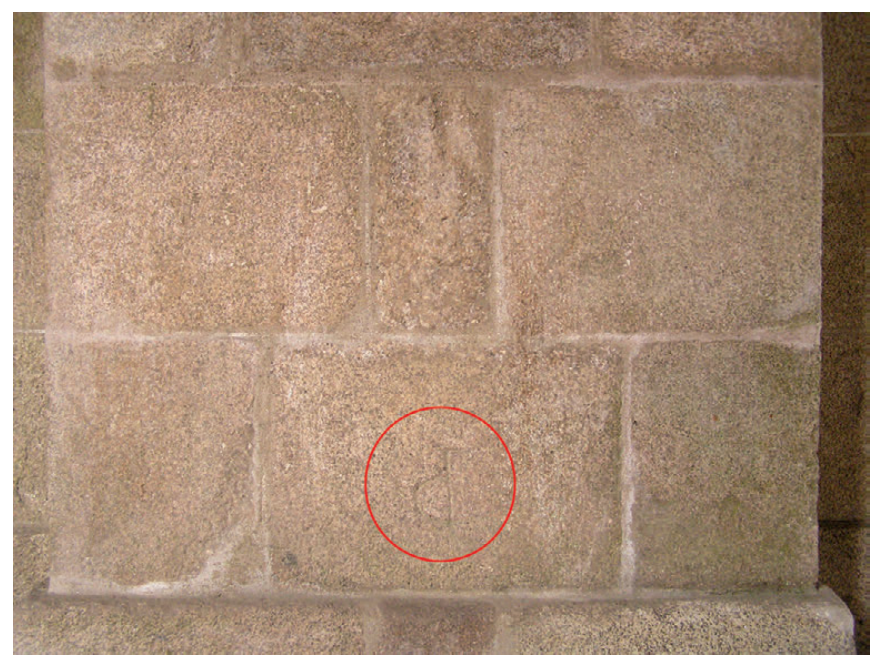

Figura 4. Marca de cantería (P) tallada en uno de los sillares del contrafuerte románico (Fotografía de la autora)

algunos autores que, si bien son reducidos en número y extensión, ofrecen datos valiosísimos para poder acercarnos al conocimiento de alguna de sus características arquitectónicas. La segunda forma es la tipológica, el conocimiento y estudio de otras iglesias benedictinas que en la época de construcción del templo samonense ya estuviesen hechas o cuyo proceso de creación se encontrase iniciado, ver cómo eran y buscar sus características comunes. Y el último camino es el de las dimensiones, las reales de piezas arquitectónicas conservadas del templo original (Figs. 8, 9 y 10) y las recogidas en documentos escritos, que representan un punto de partida seguro para el planteamiento de las proporciones del espacio del culto románico de Samos.

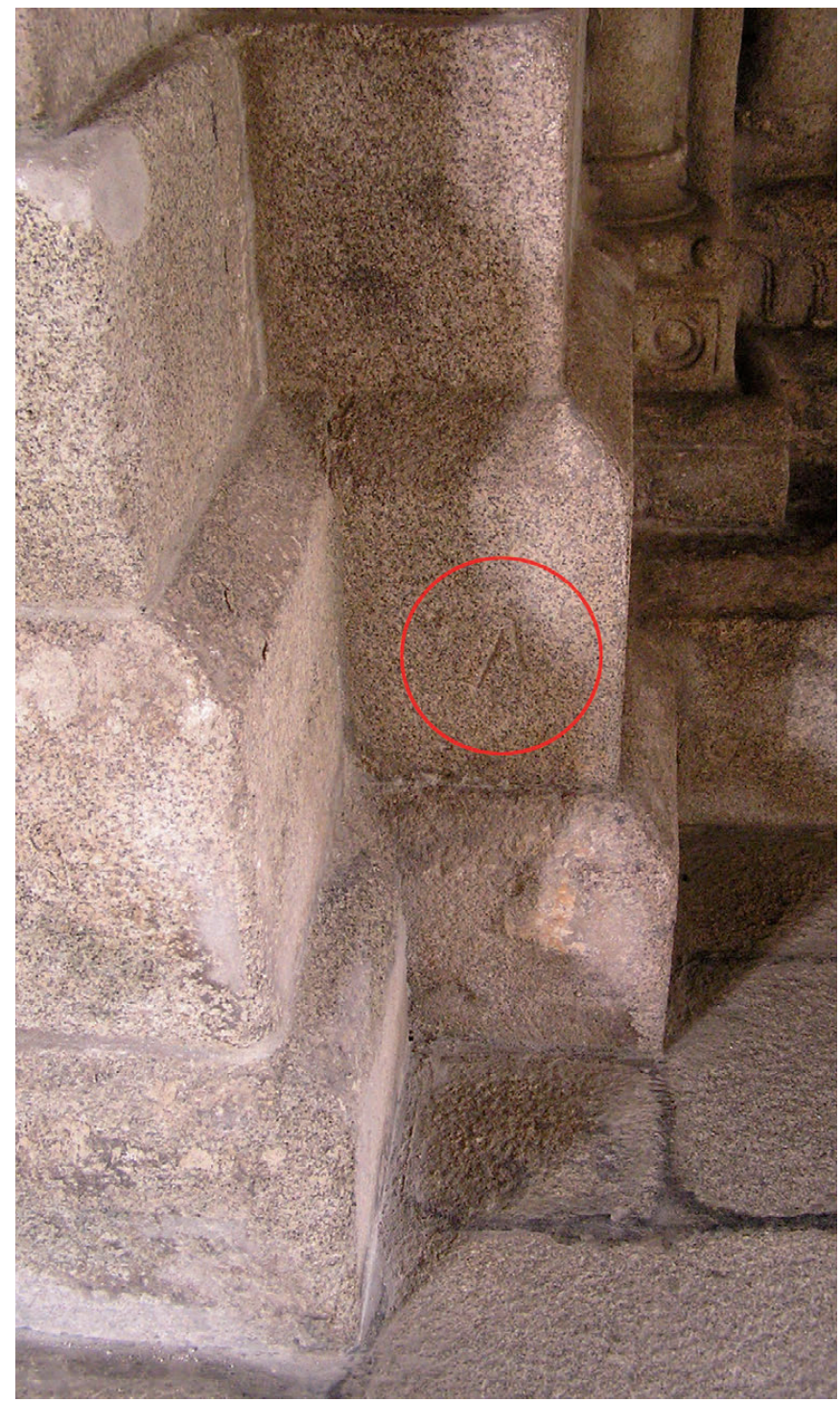

Figura 5. Marca de cantería $(\Lambda)$ tallada en uno de los sillares del contrafuerte románico (Fotografía de la autora)

\subsection{APROXIMACIÓN DOCUMENTAL}

Dentro esta vía, hemos logrado recopilar tres textos con referencias a la iglesia románica que vamos a reproducir literalmente, para inmediatamente después realizar el pertinente examen y razonamiento de cada uno de ellos. Los tres tienen en común que forman parte de trabajos contemporáneos dedicados al estudio de Samos, cuyos autores utilizaron como fuentes manuscritos que se conservaban en el archivo del monasterio hasta el año 1951, fecha del gran incendio que provocó, entre otros muchos daños, la pérdida de una gran cantidad de valiosa información sobre esta casa monástica. Son, por tanto, las únicas referencias escritas que poseemos para acercarnos al conocimiento de la configuración de 


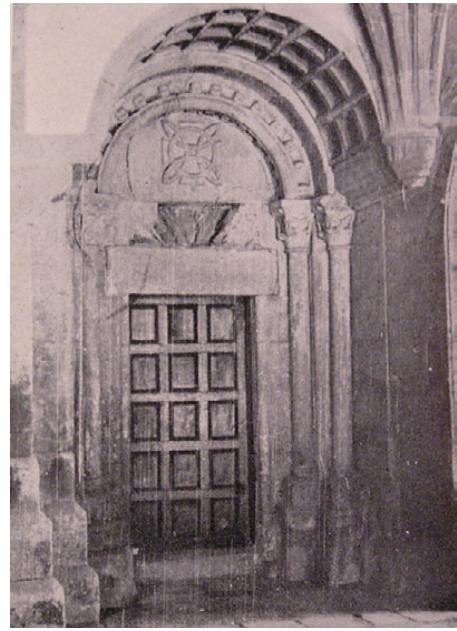

Figura 6. La portada románica en 1947 (Fotografía de Miguel Durán)

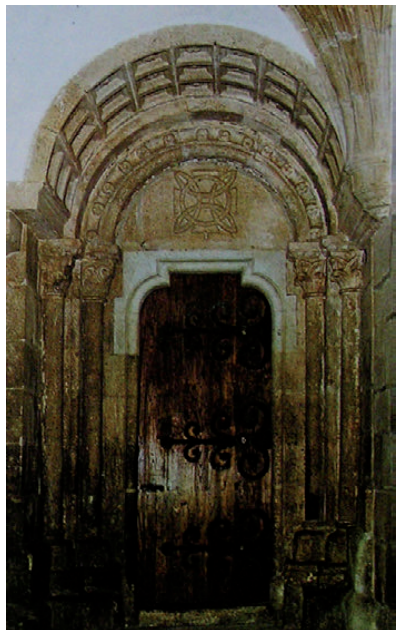

Figura 7. La portada románica en 1978 (Fotografía de Pedro de la Portilla)

la iglesia medieval desaparecida, hecho que justifica su utilización.

El primer texto al que hacemos referencia es de Manuel Castro en $1912^{14}$ :

"En el siglo XIII se reconstruyó la iglesia, pues a esta época pertenecen los escasos restos que de ella se conservan. (...)

La planta de la iglesia, orientada como todas las de su época según acusan los restos existentes de sus muros, era una cruz latina, de dimensiones, sino iguales, poco menores que las de la actual. Estaba abovedada y tenía tres ábsides, probablemente semicirculares, en correspondencia con las tres naves en que se hallaba dividido el brazo mayor por dos series de cuatro ó cinco arcos cada una, sin incluir en este número los grandes torales del crucero.

En el fondo de cada una de las naves laterales $e$ incluyendo el compartimento inmediato a la fachada, se alzaban dos torres cuadradas, terminadas en chapiteles de poca altura* y destinadas: la una al reloj y la otra a las campanas. **” El autor añade dos notas a pie de página: "*Según un dibujo antiguo" $y$ "**Las siguientes noticias están fielmente tomadas de un manuscrito anónimo del año 1723 que con el número 7 se halla comprendido entre los "Papeles varios", del tomo 23 de este titulo, que perteneció al Ilmo. Sr. D. Fr. Antonio Sarmiento Sotomayor, Obispo de Mondoñedo y actualmente posee el Monasterio de Samos."

\footnotetext{
${ }^{14}$ Castro, 1912, p. 115
}

El siguiente texto que reproducimos pertenece al mismo autor y publicación que el anterior, pero en este caso transcribe un documento de finales del siglo XVII, muy útil para comprender cómo se organizaba el espacio interior del templo:

"Volviendo a la antigua iglesia y en confirmación de lo que referente a ella queda dicho, transcribiré la parte más curiosa del acta que encabeza el 'Libro de Visitas, Bautizados, Casados y Difuntos de la Parroquial Capilla de Santa Gertrudis, sita en nuestra Monasterial Iglesia de San Julián el R. de Samos'

'Visita del año 1684-Nos el M. ${ }^{\circ}$ Fr. José Valdés, P. dor Gral. de la Religión de San Benito, Abbad y Sr. de Samos en lo espiritual y temporal, nullius dioecesis é inmediato á la sede Aplica, habiendo visitado el altar de Santa Gertrudis, sito en nuestra R. ${ }^{l}$ y Monasterial Iglesia de San Julián el R. 'de Samos, fabricado y señalado para capilla parroquial de la villa y demás feligresía...

Considerando su $R^{\text {ma }}$... que por hacer merced hasta aquí y gracia los Sres. Abbades y Convento a sus criados únicos y pocos vecinos de la villa de Samos, enterrándolos en su Iglesia, no tanto por Parroquianos como por tales criados, sin llevarles derechos de sepultura, y perdonándoles las primicias, muchas familias assi de Nra. Abbadia, como de fuera, se han entrado a vecindar en dicha nuestra villa y más términos de la Parrochia, en grave perjuicio assi del derecho parrochial, como de este R.' templo, adonde como se ha visto, cada uno a su elección y gusto abre sepultura como se le antoxa, dexando quebradas las losas, desigual el pavimento e indecente. Por tanto, y porque semejante abusso no passe adelante, señalamos precio a todas las sepulturas en forma siguiente:

El que quisiere le entierren desde la Rexa al primer arco y todo lo que forma el claro,* assi de la nave de Nuestra $S .{ }^{a}$ como la de $S .{ }^{a}$ Benito, haya de pagar por ella veinte y quatro $R .^{\text {ss }}=$ Por las que hay entre el claro del primer arco al segundo, doce $R \cdot{ }^{s s}=$ por las que hay desde el segundo al tercero, seys $R .^{\text {ss }}=$ las que hay desde el último arco hasta las Pessas del Relox, y desde el otro último hasta la Pila señalamos por sepulturas para pobres de solemnidad y para niños de hasta seys años de edad, y esta sin pagar, ni pensión alguna. Y para que este nuestro mandato tenga el debido cumplimiento, Mandamos en virtud de Santa Obediencia y pena de excomunión mayor, canon latae sententiae, á todos los sepultureros, aunque sean criados nuestros, no sean osados á abrir sepultura para nadie sin dar primero cuenta al P. Sacristan, al que 
debaxo del mismo precepto Mandamos haga un libro o cartapacio en que escriba el dia, mes y año en que cada uno fue enterrado y en que parte etc.

Dada en nra. Cámara Abbacial á quinze de Julio de mil y SS.tos y ochenta y quatro años $=E l$ Abbad y S.or de Samos=Por mandato de su R. ${ }^{\text {ma }}$ Fr. Joseph Lozano: Scro.'

A partir de esta fecha se hacen inscripciones señalando el lugar de las sepulturas p. ej. "Junto á la rexa de N. P. S. Benito'. - 'Enterróse en el tercer arco de Nuestra $S .{ }^{a}$ arco segundo'. - 'Enterráronle en el tercer arco delante de nro. P. S. Benito'- 'Cuarto arco de la capilla (nave) de N. S. ${ }^{a}$ - 'Debajo de las pesas del Relox', etc.",15

El tercer y último texto al que nos referimos es de Miguel Durán en $1947^{16}$. Dice así:

"En el archivo del Monasterio existe la siguiente descripción de la Iglesia antigua: 'Estuvo emplazada en el claustro grande y tenía tres naves como la nueva, hallándose colocados los altares con el mismo orden que en ésta. Los libros parroquiales llaman a una de las naves de Nuestra Señora; a otra, de Nuestro P. San Benito, y a la del centro, de las pesas del reloj. La entrada debía de ser la que indica un grande arco de piedra que hay en el muro de la Iglesia nueva, el cual arco está rellenado de pizarra, pues se dice que fue inhumada una persona en la nave de Nuestra Señora, en la parte que da contra la entrada.

La portada buena que hay en el claustro pequeño (la que hoy existe) era ciertamente la capilla del Santo Cristo, y alli se debía entrar desde la nave del centro por uno de los arcos señalados en dicho claustro, esto es, por el más próximo a la portada. Por debajo del otro arco contiguo debian caer las pesas del reloj, de las que se habla muchas veces en un libro de defunciones. Hay otro arco a mayor distancia, y por él se debía de entrar al signo, para salir después a la nave de San Benito. Indudablemente, la Iglesia antigua estaba orientada como la nueva y tenía torres de que carece ésta.',

\footnotetext{
15 Castro, 1912, pp. 192-194.

${ }^{16}$ Durán, 1947, pp. 31-39. El autor cita como fuentes utilizadas dos manuscritos del P. Sarmiento: "Entre los escritos referentes a los orígenes de Samos son muy notables los debidos al eruditísimo P. Sarmiento* (Este manuscrito del P. Sarmiento fue reproducido en el libro de López Peláez: "El Monasterio de Samos", La Coruña, 1894), y en lo que respecta a la cronología de sus abades y vicisitudes del monumento es de gran importancia e interés el manuscrito titulado "Relación sucinta de los sucesos principales del Real Monasterio de San Julián de Samos desde el año 759, en que se fundó, hasta el presente de 1723". Ibidem, p. 9.
}

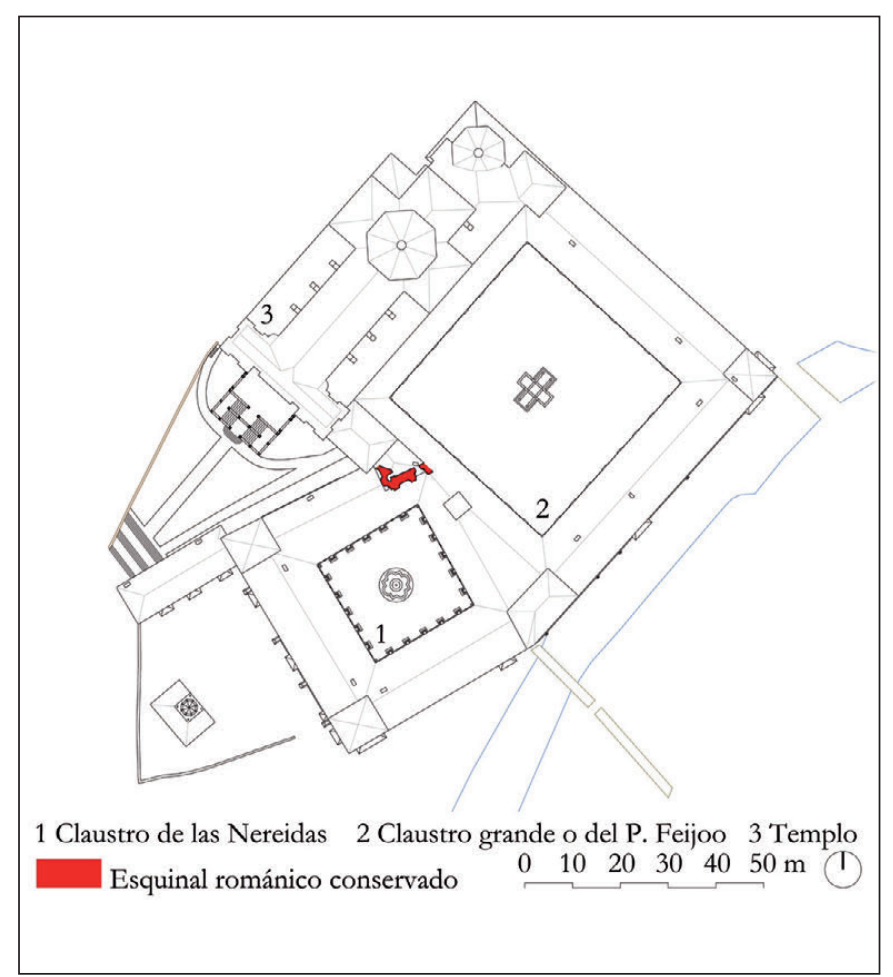

Figura 8. Planta del monasterio de Samos en la actualidad, señalando en rojo la ubicación del esquinal de la desaparecida iglesia románica que se conserva (Plano de la autora)

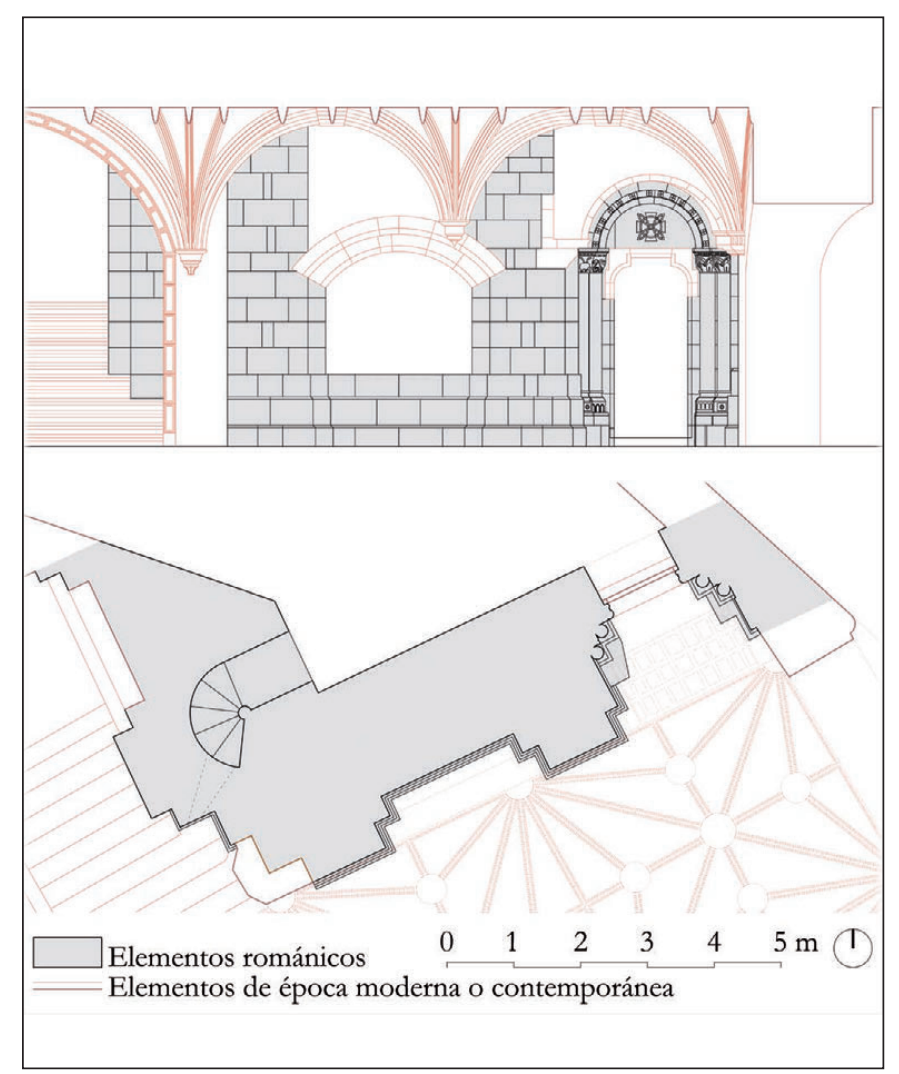

Figura 9. Dibujo en planta y alzado de la planta baja del esquinal románico (Planos de la autora) 


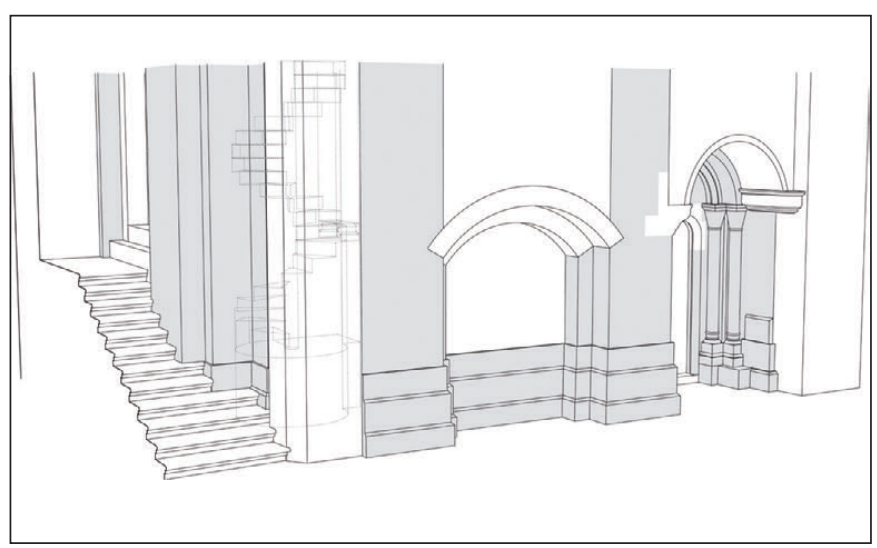

Figura 10. Axonometría de la planta baja del esquinal sur de la iglesia románica de Samos en la actualidad, señalando en gris la estructura muraria románica visible (Dibujo de la autora)

Aunque sólo dispongamos de los pequeños fragmentos anteriores, de su lectura se desprenden todo un conjunto de datos para poder recrear el aspecto de la iglesia medieval en el momento de su construcción.

Para empezar el templo románico samonense estaba orientado litúrgicamente, es decir, según eje este-oeste, con la cabecera hacia el oriente y con la fachada mirando a poniente. Su planta era de tipo basilical, con tres naves con tres ábsides — que, de momento, sólo tenemos base para decir que podrían ser semicirculares- y un crucero, estructura que refleja en su conjunto la importancia de la comunidad para la que fue construida. Asimismo, a través de estos textos sabemos que la iglesia poseyó dos torres, una destinada al reloj y la otra a las campanas, más adelante analizaremos si estas torres formaban parte de la iglesia desde su construcción inicial o si, por el contrario, fueron resultado de una reforma de una etapa posterior.

En cuanto al número de tramos que conformaban las naves de la iglesia románica, aunque a través del primer texto de Manuel Castro parece que podríamos deducir que las naves estaban formadas por 4 ó 5 tramos, pues dice "se hallaba dividido el brazo mayor por dos series de cuatro ó cinco arcos cada una, sin incluir en este número los grandes torales del crucero" ${ }^{17}$; la lectura del acta de 1684, nos lleva a interpretar que en realidad el número de tramos en el que se dividían las naves era de tres, sin contar el espacio del transepto.

En función del lugar en el que se ubicaba una tumba, la tasa a pagar por ella era distinta, lo cual obligó al monje de 1684, a detallar por escrito cuál era el coste de cada lugar de enterramiento. De esa descripción, se

\footnotetext{
17 Castro, 1912, p. 193
}

puede deducir cómo se distribuía el espacio interior del templo. Así sabemos que tras los tres ábsides de la cabecera se desarrollaba el crucero o transepto. La separación entre ellos tenía lugar mediante una reja. El ábside central acogía el altar, posiblemente dedicado a los patronos del monasterio, San Julián y Santa Basilisa; mientras que de los ábsides laterales, uno estaba dedicado a la Virgen y el otro a San Benito, de ahí se desprende el nombre de las naves correspondientes ${ }^{18}$. En el espacio entre la reja de los ábsides y el que llamaba "primer arco", que sería el que marcaba el fin del crucero y el inicio de las naves, era donde el coste del enterramiento era mayor, por ser el ámbito más próximo al altar. La siguiente zona se desarrollaba entre el llamado "primer arco" y el "segundo arco", que era el tramo de las naves más próximo al crucero, en el cual se reducía el valor económico de las sepulturas respecto al anterior. La distancia entre el "segundo arco" y el "tercero" se correspondía con el segundo tramo de las naves contando desde el crucero. Finalmente, se describe el tercer y último tramo, como aquel que se desarrollaba entre el tercer y último arco hasta la fachada. En este caso, se hizo referencia a dos lugares que serían en realidad los dos últimos tramos de las naves laterales, ya que se dice que era el espacio desde un "último arco" a "las Pesas del Reloj" —entendemos que se refiere a la torre que tenía ese nombre por acoger el reloj-, y añadió, "desde el otro último hasta la Pila”, que sería el otro último arco de la nave lateral hasta el tramo de la fachada correspondiente a ella, espacio en el que se ubicaba la pila bautismal. Estas dos últimas partes, por ser las más alejadas de la cabecera, se destinaban al enterramiento, sin coste alguno, de pobres y niños. El hecho de que en ese tramo final se detallasen de forma precisa, sólo como lugar de enterramiento, las zonas correspondientes a las naves laterales, nos da pie a pensar que en los otros casos también se esté refiriendo a ellas, dejando excluida la nave central, que probablemente era una zona reservada al coro de los monjes. Con la reunión de todos los datos anteriores, podemos elaborar un primer esquema de la posible planta del templo románico de Samos (Fig. 11).

\footnotetext{
${ }^{18}$ Las advocaciones de los tres altares de la cabecera en la iglesia románica original nos son desconocidas, al menos hasta el siglo XVII, cuando el escultor Francisco de Moure diseńó tres altares absidales nuevos, de los cuales sólo se conservan los dos colaterales, de San Benito y la Virgen, mientras que del central tan sólo han llegado hasta nuestros días las representaciones de San Julián y Santa Basilisa. De la Portilla Costa, 2001, pp. 148-163; López Calderón, 2008, pp. 193-208.
} 


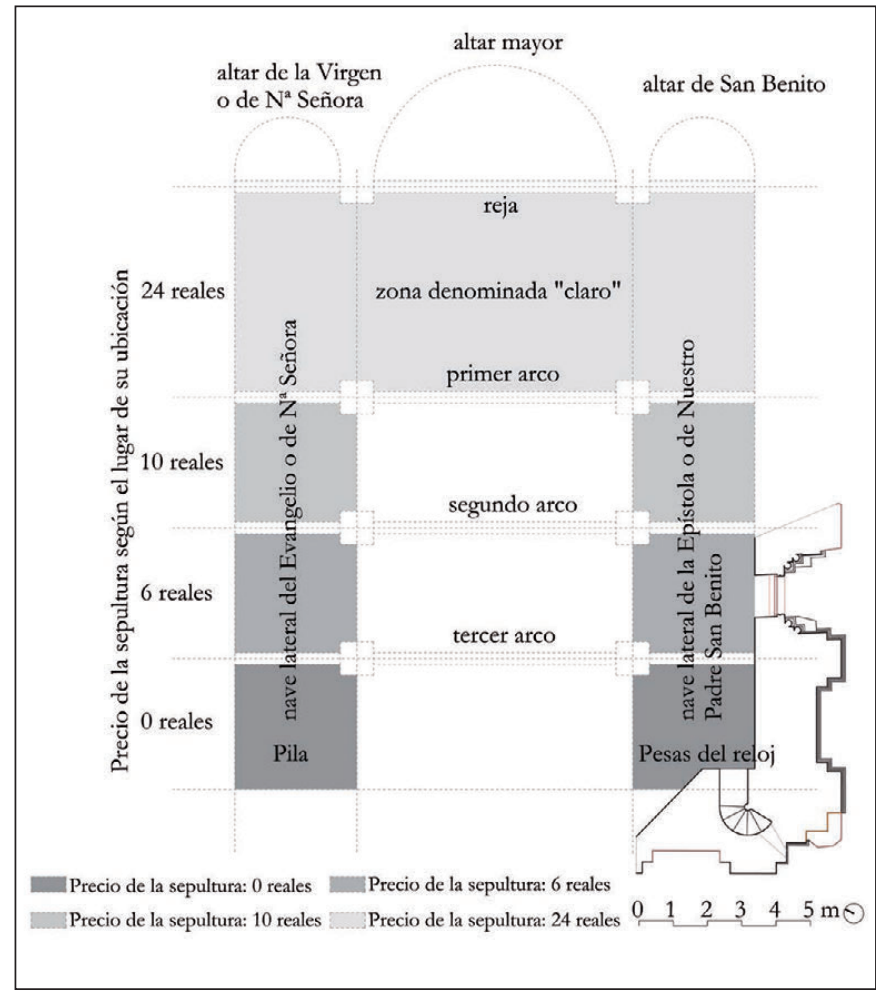

Figura 11. Esquema de la planta románica de Samos resultado de la interpretación del texto de la visita de 1684 (Dibujo de la autora)

\subsection{ANALOGÍAS TIPOLÓGICAS}

La segunda vía para llegar a plantear una recreación hipotética de cómo fue la primera iglesia medieval samonense es la que hemos llamado tipológica que, como su propio nombre indica, nos conduce al estudio del "tipo" de iglesia que reúne en sí las cualidades propias de las construcciones benedictinas de la época en la que fue realizada la de Samos, es decir, tenemos que conocer el modelo que en ese periodo artístico se convirtió en el ejemplo a imitar.

En el territorio gallego, la corriente dominante en el arte románico fue la compostelana, por la fuerte influencia que la construcción de la catedral de Santiago ejerció en cuanto a sus propias soluciones constructivas. Los inicios de las obras, en la segunda mitad del siglo XI, se enmarcaron en un contexto caracterizado por el crecimiento de la peregrinación jacobea, en cuyo impulso jugaron un papel fundamental los monjes benedictinos, especialmente los que pertenecían a la abadía de Cluny, en la Borgoña francesa.

Sin embargo, la mayoría de templos elevados en Galicia durante los siglos XI y XII eran de reducidas dimensiones, con el fin de servir como iglesias parroquiales de pueblos pequeños. Tan sólo las iglesias de los monasterios llegaban a alcanzar un tamaño mayor, pero en cualquier caso moderado si lo comparamos con la envergadura de la fábrica catedralicia compostelana.

Si bien el número es escaso, en la región gallega todavía se conservan algunos buenos ejemplos de iglesias de antiguos monasterios benedictinos, con dimensiones menores que la nueva catedral y más apropiadas a las comunidades monásticas gallegas, que en aquella época contaban con comunidades poco numerosas (Fig. 12). El modelo tipológico más extendido entre estas construcciones fue la planta basilical, formada de tres naves, crucero sólo marcado en planta y no sobresaliente en alzado, y cabecera con tres ábsides, el central más destacado ${ }^{19}$. Con esta disposición se conseguía un espacio muy bien organizado para las funciones requeridas por las comunidades monacales, de ahí el éxito de su utilización.

Sigue este arquetipo la iglesia del monasterio de San Salvador de Bergondo (Bergondo - A Coruña), perteneciente a un antiguo conjunto monástico benedictino, del cual la parte que mejor se conserva es la iglesia, con tres naves, la central más ancha que las laterales, crucero poco desarrollado en planta y no sobresaliente, y cabecera formada por tres ábsides semicirculares, precedidos de un tramo recto. Esta iglesia coruñesa también mantiene, con pequeños cambios, su primitiva fachada, dividida en tres tramos por marcados contrafuertes, abriendo en la parte central una sencilla portada. Hay constancia documental de que este monasterio existía ya en el año $1138^{20}$.

También de la segunda mitad del siglo XII y de planta basilical, con tres naves de cinco tramos, rematadas en sus ábsides correspondientes, es la iglesia monasterial de San Julián de Moraime (Muxía - A Coruña), cuya pertenencia a la orden de San Benito consta desde $1105^{21}$.

La iglesia de San Martiño de Xuvia (Narón - A Coruña) es muy similar a nivel planimétrico a la anterior. La existencia de un monasterio en este lugar está documentada desde finales del siglo X. En la misma provincia que los ejemplos anteriores, pero todavía con menor dimensión, se encuentran otros dos casos de iglesias de antiguos monasterios benedictinos, con planta basilical de tres naves, desarrolladas en tres tramos y rematadas en sus respectivos ábsides semicirculares. Nos referimos a Santa María de Mezonzo (Vilasantar - A Coruña) y San Tomé de Monteagudo (Arteixo - A Coruña).

\footnotetext{
19 Valle Pérez, 2001, pp. 114-115; Bango Torviso, 2003, pp. 218-219.

20 Del Castillo, 2008, p. 62.

${ }^{21}$ Ibidem, p. 349.
} 


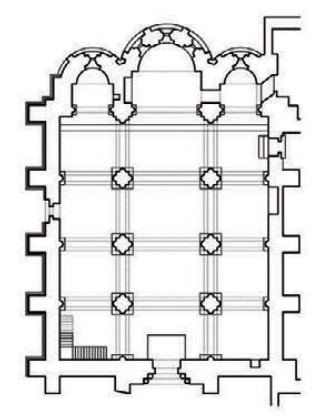

Planta de la iglesia de San Salvador de Bergondo (Bergondo - A Coruña) $\ominus$

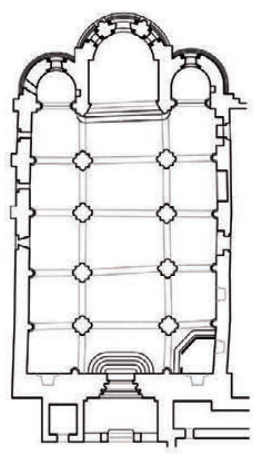

Planta de la iglesia de San Martiño de Xuvia (Narón - A Coruña)

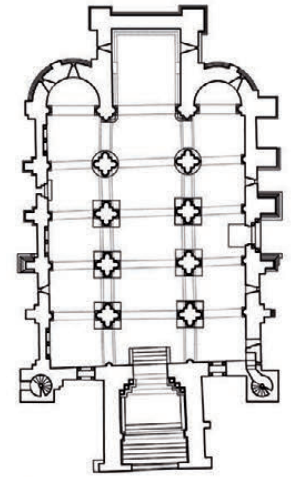

Planta de la iglesia de San Julián de Moraime (Muxía - A Coruña)

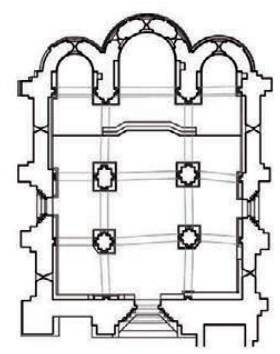

Planta de la iglesia de Santa María de Mezonzo (Vilasantar - A Coruña)

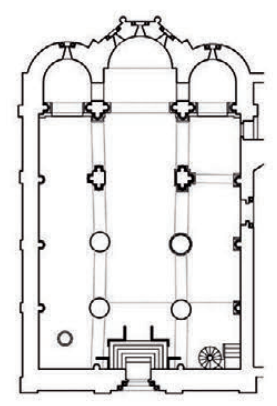

Planta de la iglesia de Santa María de

Penamaior

(Becerreá - Lugo) (Arteixo - A Coruña)

Planta de la iglesia de San
Tomé de Monteagudo

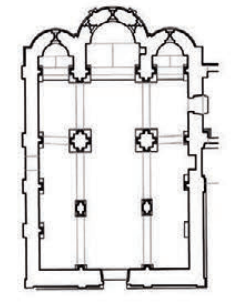

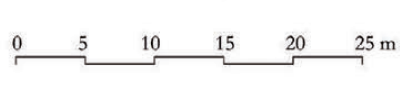

Figura 12. Modelos tipológicos de iglesias románicas de antiguos monasterios benedictinos gallegos (Franco Taboada, 2001; excepto la planta de la iglesia de San Tomé de Monteagudo que es un dibujo de la autora)
Pero los modelos más próximos a nivel geográfico al caso que nos ocupa, son los de las iglesias de los antiguos monasterios de Santa María de Penamaior (Becerreá - Lugo), San Vicente de Pombeiro (Pantón - Lugo) y San Esteban de Ribas de Sil (Nogueira de Ramuín - Ourense).

La existencia de una comunidad cenobítica en Penamaior, consta desde el año 919, cuando fueron enviados desde allí varios monjes al monasterio de Samos. Su iglesia románica fue construida en 1177, según una inscripción, por tanto a nivel temporal, esta construcción fue coetánea de la de Samos, y anterior a que el monasterio de Penamaior se convirtiese en casa cisterciense. San Vicente de Pombeiro es otro buen ejemplo de iglesia románica de planta basilical de tres naves y cabecera triabsidal, con magníficas portadas conservadas del mismo estilo en sus tres fachadas.

Y, por último, el caso de San Esteban de Ribas de Sil, con una iglesia abacial que sigue la tipología benedictina propia de la época, aunque sobre ella se hayan realizado cambios en fases posteriores. El inicio de las obras de construcción de este templo, según una inscripción ubicada en una columna de la cabecera, se remonta al año $1183^{22}$, pudiendo considerarse que los trabajos se prolongarían hasta principios del siglo XIII. Por tanto, temporalmente su construcción fue pareja a la de la iglesia de Samos, cuya obra recordemos que los documentos sitúan aproximadamente entre 1167 y 1228. Exteriormente, aunque la fachada principal del templo ha sufrido importantes cambios, todavía mantiene elementos de la original, como los contrafuertes que la dividen en tres tramos y el rosetón de la parte superior, hoy cegado.

En cualquiera de los ejemplos anteriores vemos modelos reales conservados en Galicia, que bien pueden utilizarse para, por analogía tipológica, elaborar una planta hipotética de la iglesia románica de Samos en el siglo XIII, sin olvidar tener presentes todos los datos extraídos de la documentación escrita analizada anteriormente, que vienen a confirmar que el espacio de culto samonense siguió el modelo tipológico habitual de templo monástico, implantado en el territorio gallego.

\subsection{REALIDAD ARQUITECTÓNICA}

Resta ahora hacer uso de un último recurso, el de las dimensiones, para que la solución hipotética planteada sea lo más próxima posible a la realidad desaparecida.

\footnotetext{
22 Franco Taboada, 2001.
} 


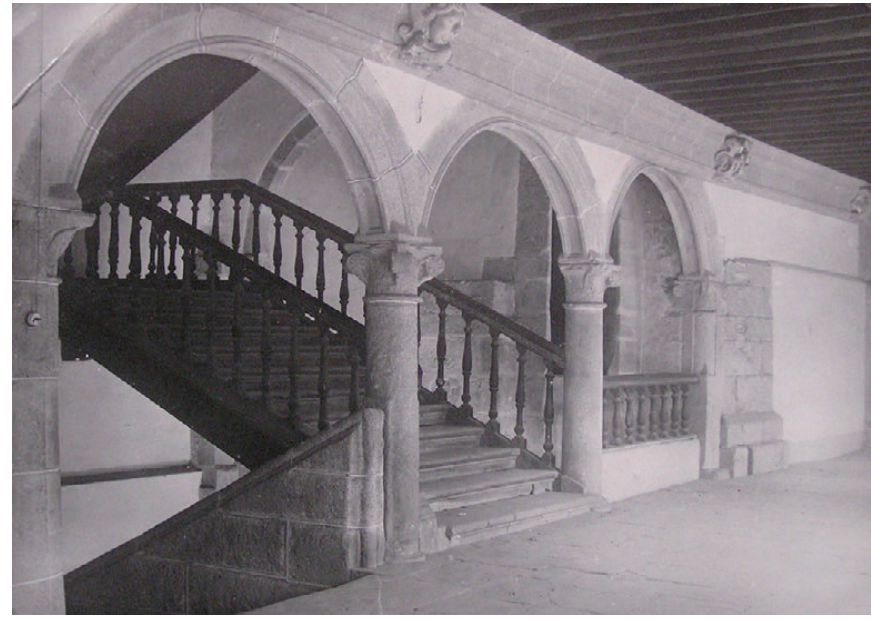

Figura 13. Restos del esquinal sur románico a la altura de la segunda planta del claustro de las Nereidas, en la primera mitad del siglo XX (Fondo fotográfico del Monasterio de Samos)

Caminar por el ámbito de las medidas nos conduce en primer lugar a mirar hacia las piezas arquitectónicas que perviven del templo medieval. Ya anunciábamos al comienzo de este artículo que esas piezas son pocas, pero ofrecen una información certera.

Centrando de nuevo nuestra mirada en el esquinal sur conservado, nos aporta, de forma fidedigna, la orientación del templo, que se desarrollaba desde esa posición hacia el noreste, extendiéndose en dirección a lo que hoy es el claustro grande o del P. Feijoo. Se trata de un muro pétreo que se resuelve con unas partes vistas ejecutadas en cantería de granito, con grandes sillares dispuestos en hiladas uniformes, y otras zonas hoy recebadas y pintadas (Fig. 27). Posee 8' $50 \mathrm{~m}$ de longitud en su cara sureste y $6 \mathrm{~m}$ en el frente suroeste, con 2'52 m de anchura en la zona del contrafuerte y 1'80 m en la parte carente de él, alcanzando $3 \mathrm{~m}$ en la zona más ancha de la torre. En altura, el esquinal se prolonga hasta la planta segunda del claustro de las Nereidas, donde todavía hoy son visibles sus restos, llegando a tener en total 8'65 m. Durante la reforma del monasterio que tuvo lugar en los años posteriores al incendio de 1951, la comunidad decidió igualar las paredes en esa zona del esquinal, lo que conllevó la eliminación u ocultación de los restos murarios románicos sobresalientes a la altura de la segunda planta, tal y como podemos comprobar con una simple comparación entre el estado actual y el de mediados del siglo XX (Figs. 13 y 14).

Tanto el contrafuerte como la portada pertenecieron sin duda al templo románico construido entre los siglos XII y XIII y creemos que también la torre conservada es de la misma época (Fig. 15). Existe constancia documental, en

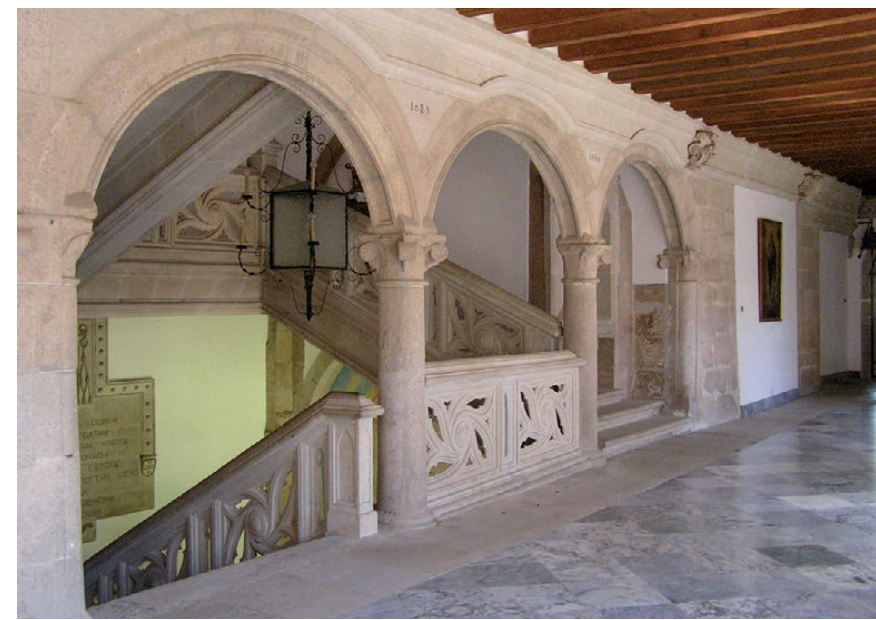

Figura 14. Restos del esquinal sur románico a la altura de la segunda planta del claustro de las Nereidas, en la actualidad (Fotografía de la autora)

un contrato de 1621, de que el cantero Alonso Rodríguez se comprometía a "hazer ciertas torres y campanario y otras cosas" ${ }^{23}$, lo cual nos podría hacer pensar que las torres fueron construidas a principios del siglo XVII. Por otra parte, Manuel Castro atribuye al abad Mauro de Vega (1633-1637) la realización, entre otras obras, de una torre ${ }^{24}$. Sin embargo, esas dos actuaciones debieron ser obras de reforma sobre torres ya construidas o remates de las ya iniciadas, pues en nuestra observación in situ de la escalera interior de la torre sur, hemos podido reconocer en uno de los sillares, una marca de cantería similar a una CO, idéntica a la existente sobre varios fragmentos pétreos de la portada, lo cual vincula, al menos el arranque de la torre, a la misma época y cantero que construyó aquella (Fig. 16). De igual modo, en los sillares de la cara suroeste de la torre, existen otras tres marcas de cantería —una $\mathrm{F}$, una $\mathrm{V}$ y una $\mathrm{P}$ - que aparecen repetidas en la portada y el contrafuerte ${ }^{25}$.

Pero lo que más nos interesa señalar ahora, es que a través de este esquinal obtenemos varias dimensiones reales del templo antiguo (Fig. 24). La primera el ancho

\footnotetext{
${ }^{23}$ El contrato de 1621 ha sido trascrito de forma íntegra en Folgar de la Calle y Goy, 2008, Apéndice documental [CD-ROM].

${ }^{24}$ Castro, 1912, p. 117.

${ }^{25}$ Otra evidencia de que las torres fueron construidas, al menos la parte correspondiente a sus arranques, con la iglesia románica original, es que al observar la zona inferior de la hoy conservada, en su encuentro con la escalera del claustro de las Nereidas, cuya planta baja fue construida entre 1562 y 1582 , se puede identificar una continuidad en la conformación de su base — con escalones ligeramente sobresalientes en tres niveles sucesivos-, de igual factura a los que recorren el resto de los muros medievales hasta su encuentro con la portada. Este sería un recurso innecesario si las torres fueran levantadas completamente en el siglo XVII, momento en el que, al menos en el caso de la torre sur, su parte baja ya estaría oculta al exterior por su encuentro con el claustro de las Nereidas.
} 


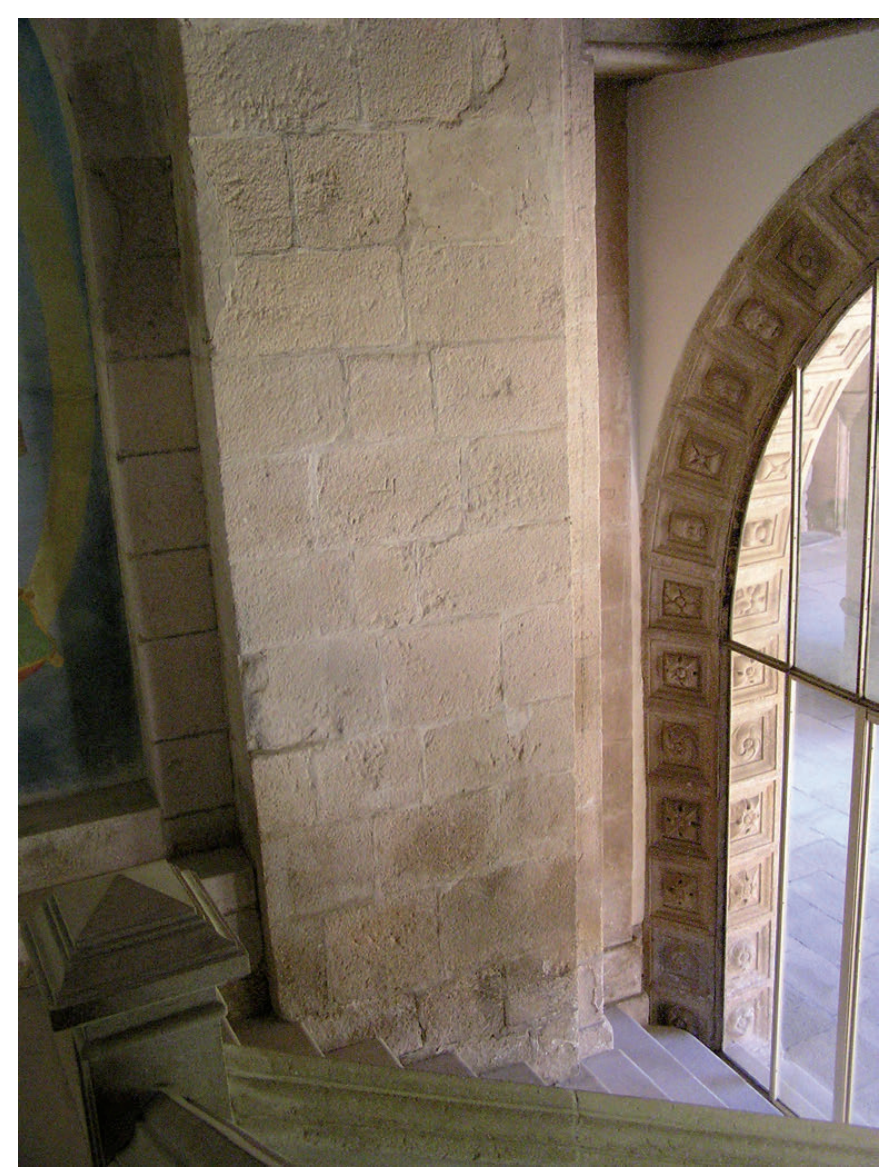

Figura 15. Zona inferior de la torre románica vista desde la escalera del claustro de las Nereidas (Fotografía de la autora)

de los muros, de 1'80 m, probablemente constante en toda la dimensión del templo. La segunda, la dimensión de un contrafuerte y su forma en planta, valores que podemos extrapolar a los demás contrafuertes que pudo tener. La tercera, la anchura del último tramo de las naves, que es la distancia entre el eje del contrafuerte conservado y el frente de acceso al interior de la escalera de caracol de la torre, en cuyo punto más estrecho son 3’20 m, y a medida que nos vamos desplazando hacia el norte, el muro se inclina hacia la línea de fachada, reduciendo su grosor respecto al que tiene en la zona de la torre, y aumentando así la anchura del último tramo hasta alcanzar aproximadamente los 3'80 m. La cuarta dimensión que podemos extraer es la altura total que alcanzaba el muro sureste de la iglesia románica, sobre 8’65 m. Este valor lo obtenemos a través de la observación y posterior dibujo sobre planimetría actual, del punto de remate de los restos de muro sobresaliente, que se aprecian en la segunda planta del claustro de las Nereidas, en la realidad y en fotografías de la primera mitad del siglo XX. La quinta y última medida que nos aporta

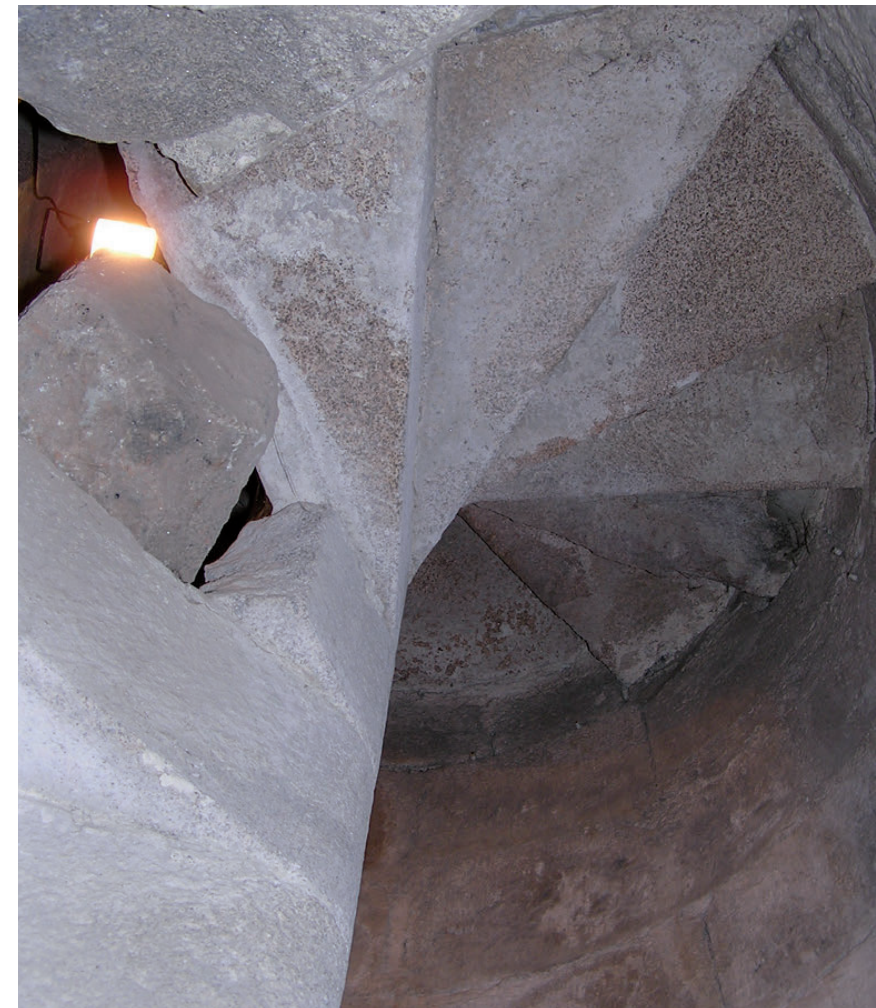

Figura 16. Escalera de caracol de interior de la torre del esquinal sur conservado de la iglesia románica, con algunos peldaños en mal estado. En algunos sillares del eje central de la escalera todavía se pueden reconocer marcas de cantería similares a las existentes en la cara exterior de los muros románicos conservados. (Fotografía de la autora)

este esquinal, es la de la anchura del segundo tramo de las naves, en cuyo extremo sur se abre la portada, que lo habitual, según los modelos tipológicos previamente estudiados, era que ocupase una posición simétrica entre dos contrafuertes. Si bien el contrafuerte izquierdo de la portada se conserva en buen estado, el inicio del derecho se puede percibir, pero está muy desfigurado, incluso mutilado, por causa de actuaciones de época posterior. Aún así, el dibujo de los restos y la consideración de la simetría en la apertura del pórtico, nos permite obtener la dimensión del tramo segundo, de 3’81 m. Medida esta última, que también podemos extrapolar al primer tramo de las naves, pues la igual dimensión de la anchura de los distintos tramos en los que se dividen las naves de una iglesia románica benedictina, es una característica propia del modelo tipológico analizado.

Para obtener más medidas del templo medieval hemos de acudir a una serie de piezas escultóricas, los retablos que diseñó Francisco de Moure a principios del siglo XVII, para amueblar y embellecer el interior de aquel. En primer lugar, se sabe que Moure fue el autor 


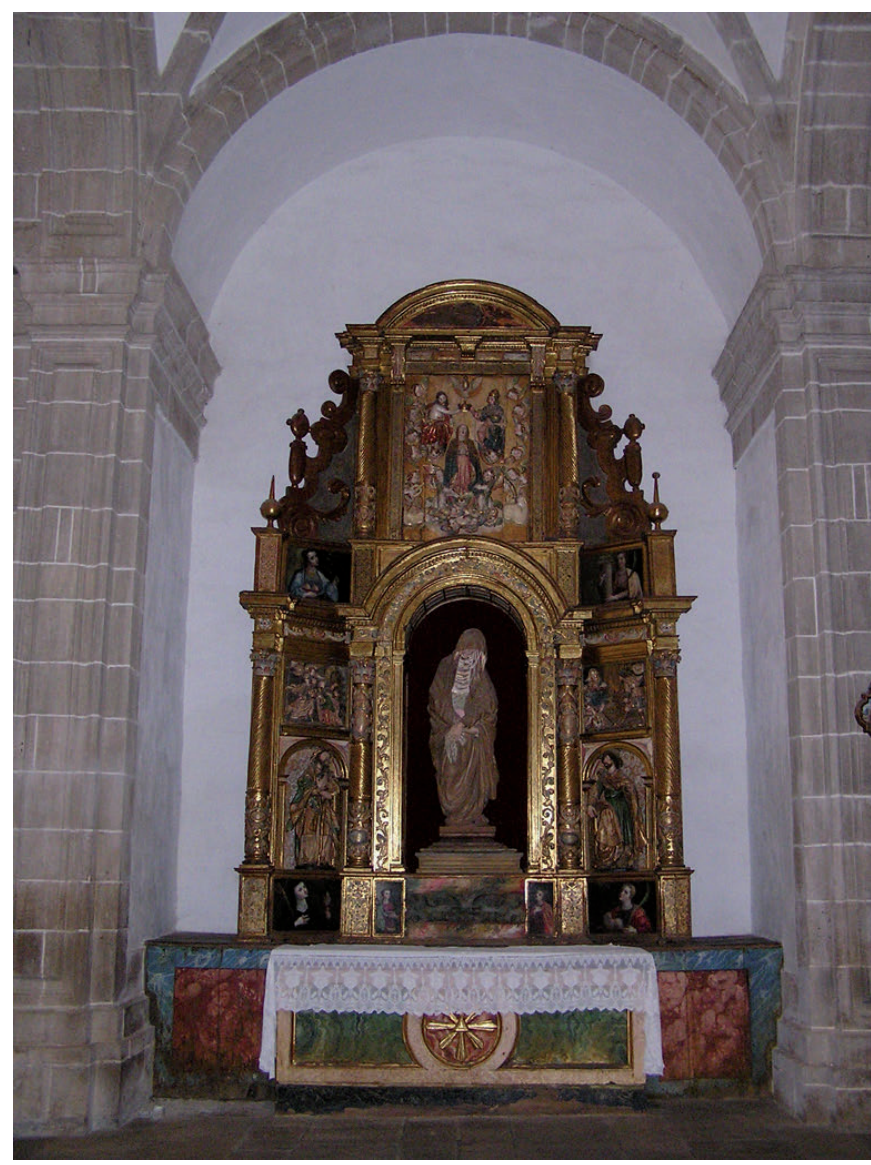

Figura 17. Retablo de la Inmaculada creado por el escultor Francisco de Moure para el ábside lateral norte de la iglesia románica (Fotografía de la autora)

del retablo mayor, hecho durante el abadiato del P. Cristóbal de Aresti (1613-1617) para la capilla principal del antiguo templo ${ }^{26}$. Este retablo fue trasladado a la iglesia actual cuando se derribó la anterior y allí permaneció hasta la construcción, en torno a 1781-1785, de uno nuevo de José Ferreiro, que provocó la pérdida de la talla barroca.

Además del anterior, el escultor Francisco de Moure ejecutó cuatro retablos más durante el mandato del abad Miguel Sánchez (1618-1621): los de San Juan y Santa Catalina, posiblemente para dos altares de las naves colaterales, y los de la Virgen y San Benito para los dos ábsides laterales de la cabecera ${ }^{27}$. Los dos primeros, de San Juan y Santa Catalina, son obras desaparecidas, de las que apenas se conservan algunos elementos. No es así en el caso de los colaterales de la Virgen y de San Benito, que se mantienen íntegros ${ }^{28}$.

${ }^{26}$ Castro, 1912, p. 117. Arias Cuenllas, 1992, pp. 221-222.

27 Ibidem.

28 Ver nota 9.

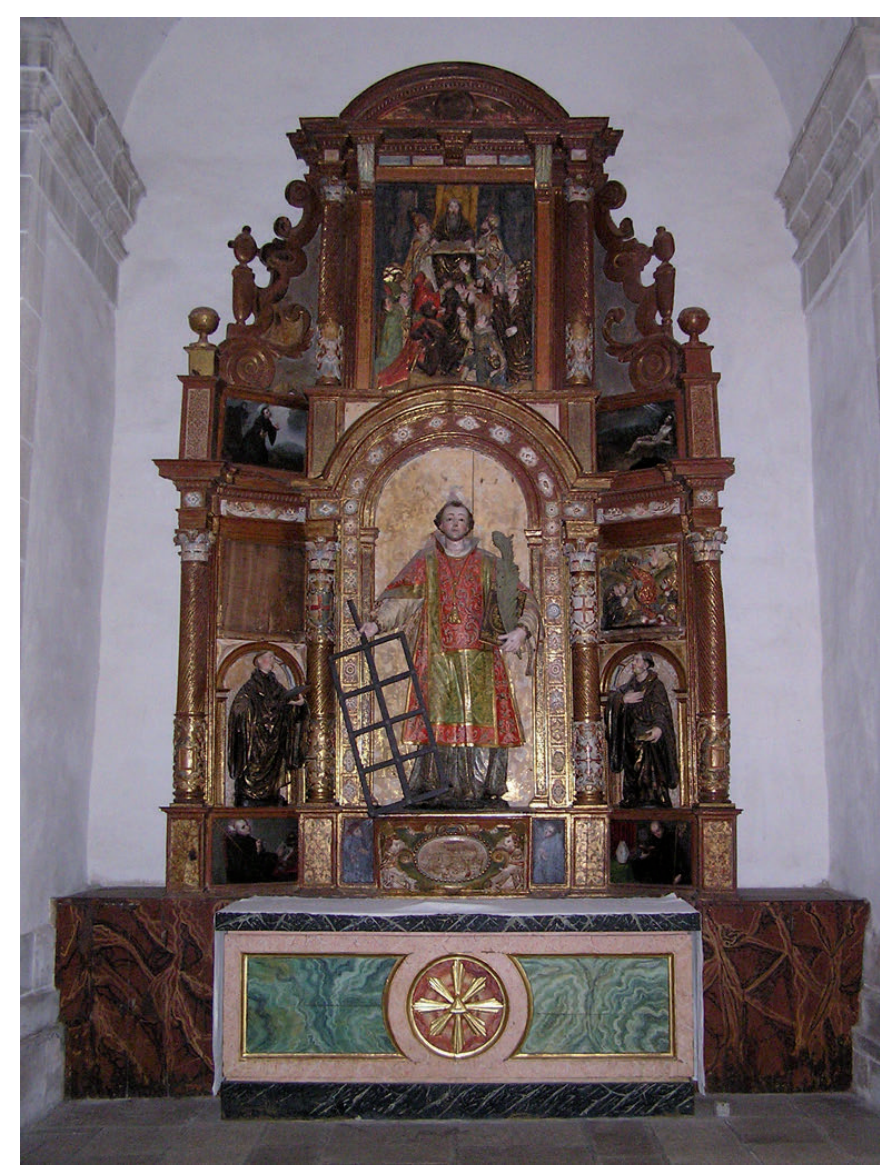

Figura 18. Retablo de San Benito creado por el escultor Francisco de Moure para el ábside lateral sur de la iglesia románica (Fotografía de la autora)

El retablo de la Virgen (Fig. 17) ocupaba en el templo medieval el ábside correspondiente a la nave del Evangelio, es decir, la norte, y la medida de su largo entendemos que equivalía a la anchura que tenía aquella, pues lo habitual es que el retablo se diseñase para extenderse a lo largo de todo el espacio para el cual era construido en su origen, y de no ser así, al menos podemos considerarlo como dimensión mínima del ábside lateral medieval en el que remataba por prolongación la nave norte.

El retablo dedicado a San Benito (Fig. 18), se situaba en el ábside de la cabecera perteneciente a la nave de la Epístola, la orientada al sur, y la dimensión de su largo era la de la anchura de la nave correspondiente; que, atendiendo a cuestiones planimétricas, debía coincidir con la de la nave sur. Hoy en día, el retablo del santo nursiano se sitúa en la cuarta capilla de la nave de la Epístola y su largo es de 3’22 m, lo que equivale a 10 pies carolingios $^{29}$, al igual que el dedicado a la madre de

\footnotetext{
291 pie carolingio equivale a 0’3219 m según Merino de Cáceres, 2000, p. 53.
} 


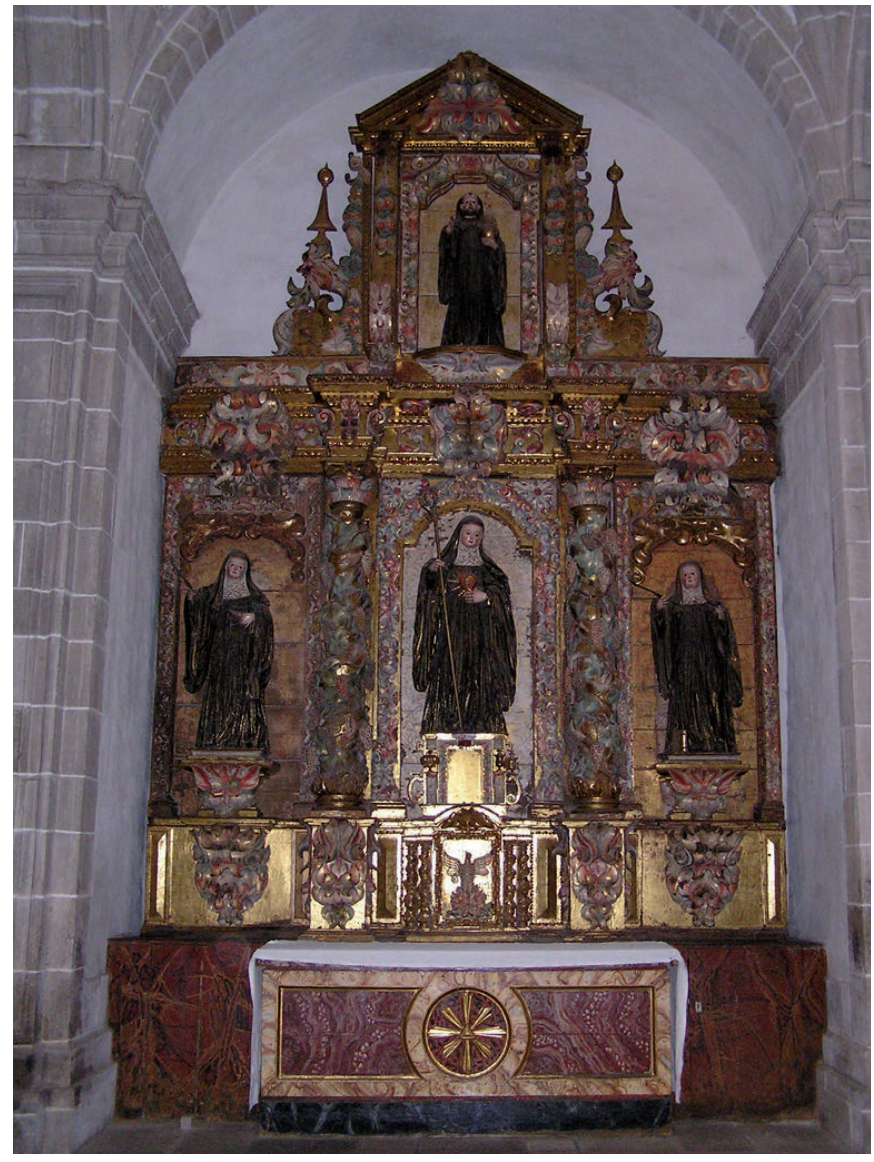

Figura 19. Retablo de Santa Gertrudis ubicado en el extremo norte del crucero de la iglesia románica y mutilado por sus lados al ser trasladado al templo actual (Fotografía de la autora)

Cristo, que está colocado enfrente, en el cuarto tramo de la nave lateral norte. Asimismo, en ambos casos, la parte posterior del retablo, con una forma curva, es un indicador más de que fueron creados para encajarse en un ábside semicircular (Fig. 20).

Justo en el tramo anterior, el tercero de la nave de la Epístola, nos encontramos con otro retablo trasladado de la iglesia medieval a la moderna, el dedicado a Santa Gertrudis (Fig. 19), cuya importancia radica en que era el altar parroquial del monasterio, situado en el extremo norte del crucero del templo antiguo ${ }^{30}$; por tanto, en este caso su largo, de 5’16 m, nos aporta la anchura interior del transepto de la iglesia medieval, que sería de 16 pies carolingios. Este retablo fue realizado durante el abadiato de José Valdés (1681-1685)31. Al ser trasladado al templo nuevo sufrió una transformación, reduciendo su longitud, para poder ser encajado en su nueva ubicación, de 4’24 m, a través de la eliminación por ambos lados de

\footnotetext{
30 Castro, 1912, p. 169.

31 Arias Cuenllas, 1968, p. 65.
}

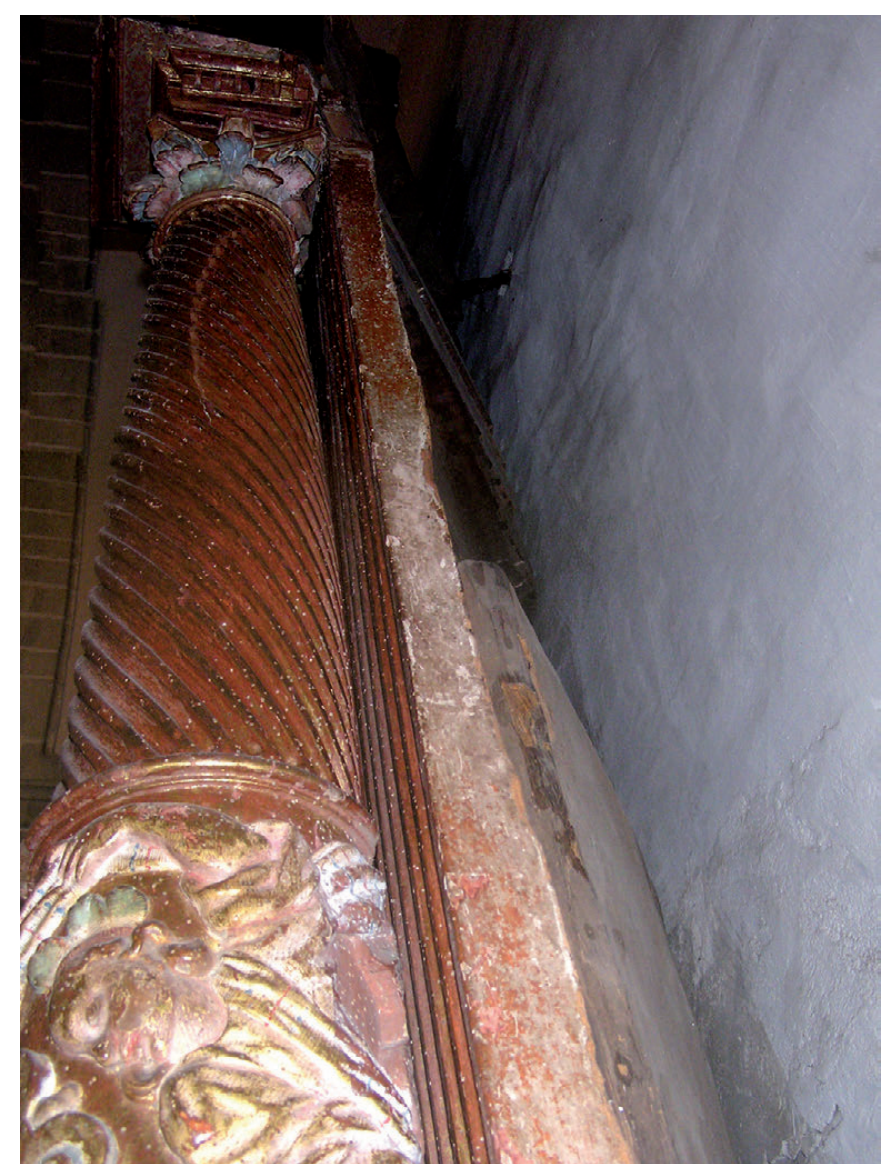

Figura 20. Parte posterior del retablo de San Benito con una forma preparada para ser encajado en un ábside curvo (Fotografía de la autora)

dos remates, que posiblemente fueran a modo de pilastras como las que todavía flaquean la imagen de la santa parroquial. Sumando la anchura de dos pilastras a la longitud del altar actual obtenemos la dimensión citada anteriormente de 5,16 $\mathrm{m}$ o 16 pies carolingios.

Después de examinar los vestigios anteriores, todavía nos falta, sin embargo, conocer cuál fue la dimensión de la capilla mayor y por extensión de la nave central. En la búsqueda de ese dato, nos tenemos que parar, primeramente, en el análisis de una pieza arquitectónica que algún autor considera que pudo pertenecer a la iglesia románica $^{32}$. Se trata de la bóveda de crucería que cubre la parte superior del último tramo de la iglesia actual (Fig. 21). Su traza nada tiene que ver, a primera vista, con la arquitectura del conjunto de la iglesia moderna y las bóvedas de cañón acasetonadas que cubren la mayor parte de su nave central. Esta circunstancia es la que ha provocado que algún estudioso del monasterio samonense la considerase procedente de la iglesia románica, donde cree

\footnotetext{
${ }^{32}$ Así lo plantea Folgar de la Calle, 2008, p. 158.
} 
que sostenía el coro alto que se construyera a sus pies a finales del siglo XVI y, de ser así, nos aportaría la anchura de su nave central. Cuando se edificó el nuevo espacio de culto y se alcanzó su último tramo -momento en el que fue necesario derribar la antigua iglesia románica-, los monjes podrían haber decidido trasladar esta bóveda de crucería, para reaprovecharla en una nueva ubicación, permitiendo, al mismo tiempo, la utilización de las cajas de los órganos, que se realizaran para el templo románico, durante el periodo en el que las obras de la nueva iglesia estuvieran paralizadas ${ }^{33}$.

Al medir el espacio que en la actualidad cubre la bóveda de crucería obtenemos unas dimensiones de 5'68 m de ancho y 9'85 m de largo. Los 5'68 m son muy superiores a los 3'80 m que existen de separación entre el contrafuerte y la torre románica conservada, y que determinan la dimensión del último tramo de las naves medievales. Por tanto, la hipótesis de que esta bóveda de crucería tuviera esa función en el pasado no es factible.

Aunque decíamos que aparentemente nada tiene que ver la bóveda de crucería con la bóveda de cañón acasetonada, sin embargo, al observar con detenimiento la sección de aquella y, al mismo tiempo, fijarse en la sección correspondiente a los nervios que definen los casetones de la bóveda de cañón próxima (Figs. 22 y 23), podemos reconocer que son idénticas, lo cual nos conduce a la conclusión de que dicha bóveda de crucería, a pesar de su tracería discordante con el resto del conjunto, fue realizada expresamente para ese lugar ${ }^{34}$.

El camino anterior no nos aporta el ancho de la nave central del templo románico. Para conocer ese valor tenemos que recurrir a un documento escrito de principios del siglo XVII, que no hemos reseñado en la vía documental, pues sólo recoge datos sobre la obra de reconstrucción de la capilla mayor primitiva. Al ser esa la parte más antigua del templo románico — pues generalmente las iglesias medievales se empezaban a construir por la cabecera-, se encontraba bastante deteriorada tras el paso de cuatro centurias. Tal y como señala el P. Maximino Arias, el 25 de septiembre de 1601, el abad Claudio Tenorio, firmó un contrato con los maestros de cantería Juan González y Alonso Rodríguez ${ }^{35}$, para que hicieran de nuevo la capilla mayor de la iglesia, la cual según lo acordado en un primer momento debía tener "veinte dos pies de ancho y treinta y un pie de largo que

\footnotetext{
33 Ibidem.

${ }^{34}$ La razón de este cambio la desconocemos, aunque profundizamos en el análisis de varias posibilidades en un apartado de nuestra Tesis Doctoral.

35 Arias Cuenllas, 1992, pp. 220-221.
}

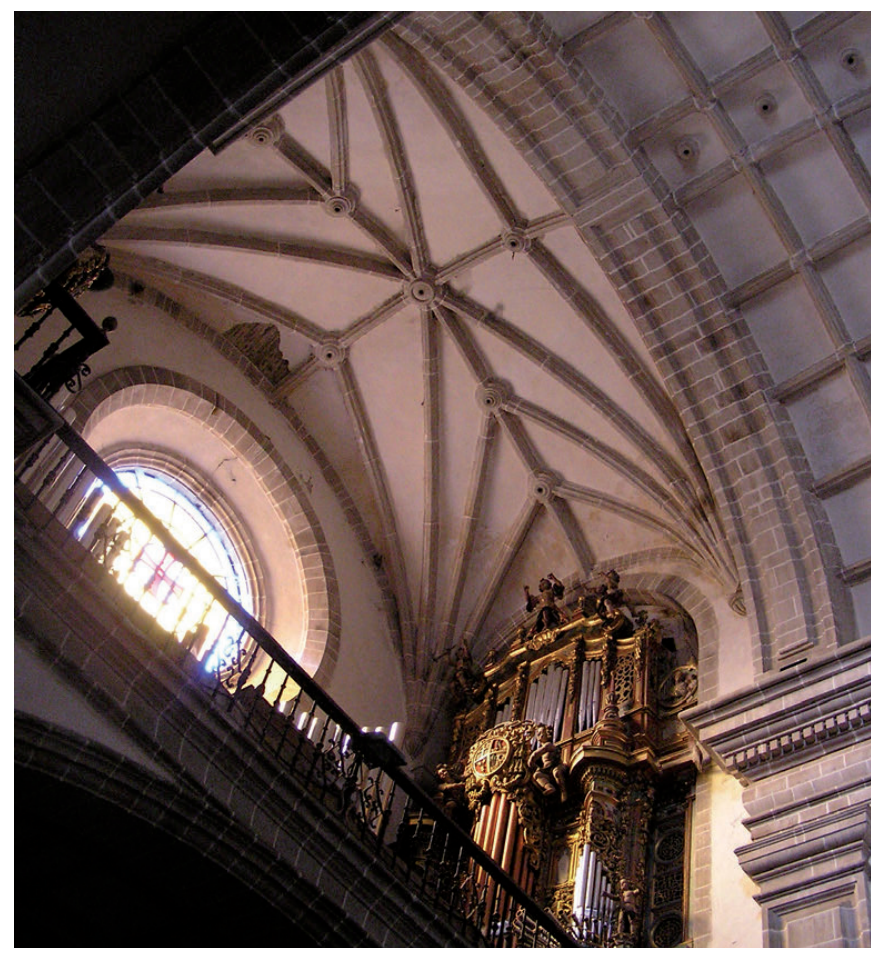

Figura 21. Bóveda de crucería que cubre el último tramo de la iglesia de Samos actual (Fotografía de la autora)

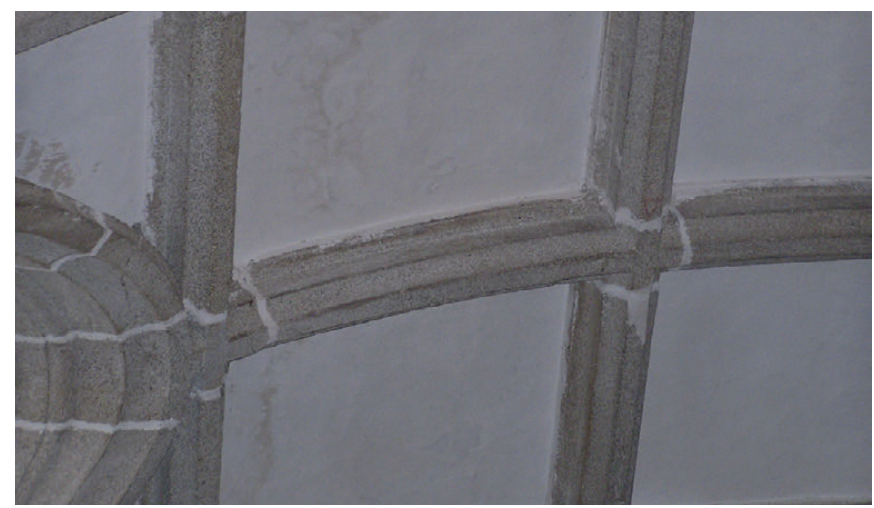

Figura 22. Detalle de los nervios que definen los casetones de la bóveda de cañón de la nave central de la iglesia de Samos actual (Fotografía de la autora)

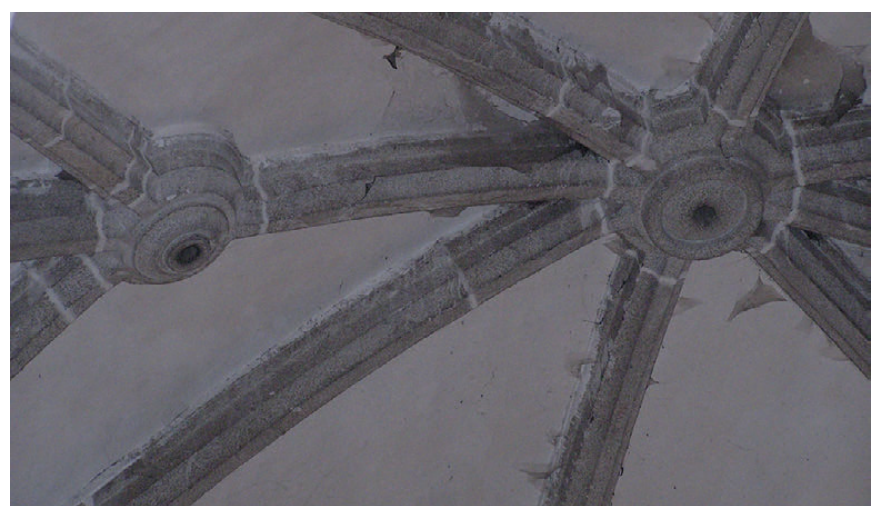

Figura 23. Detalle de los nervios de la bóveda de crucería que está situada sobre el último tramo de la iglesia de Samos actual (Fotografía de la autora) 


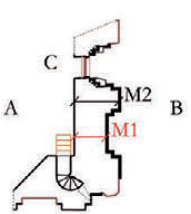

Paso 1

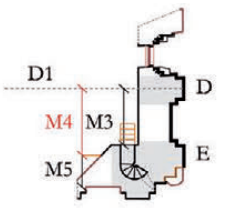

Paso 2

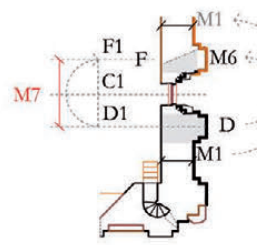

Paso 3

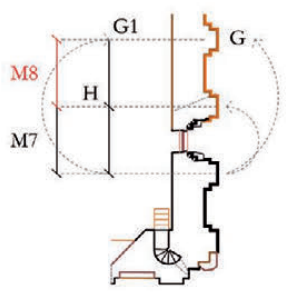

Paso 4

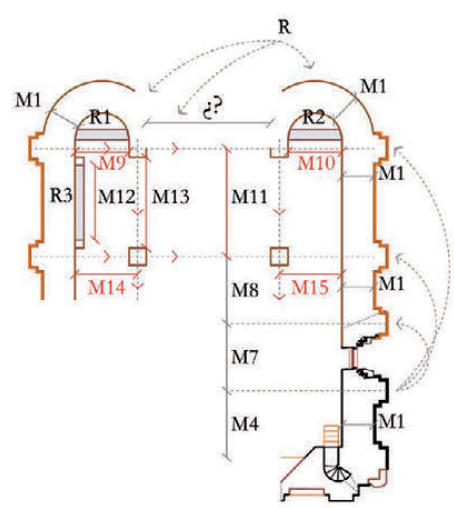

Paso 5
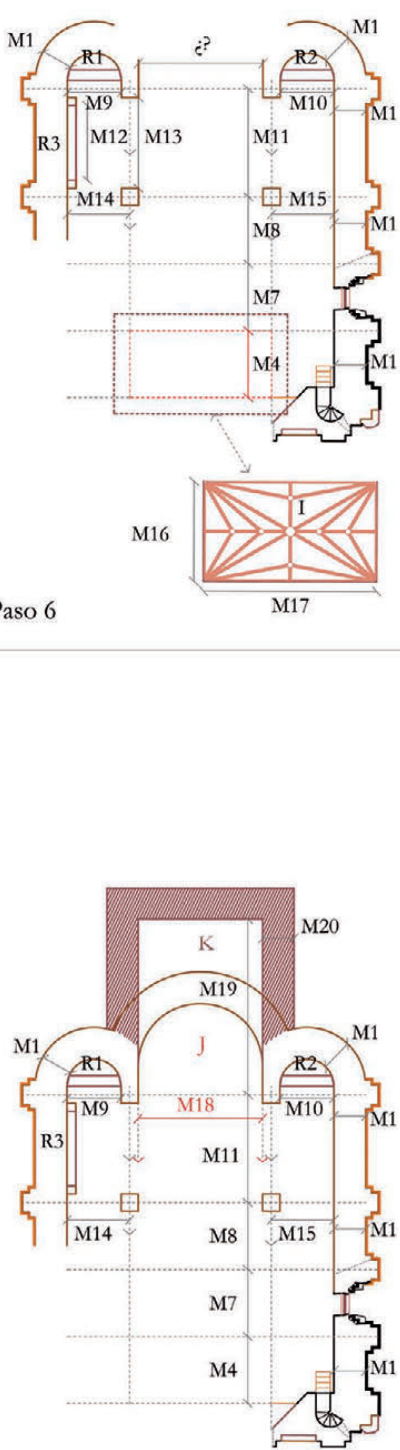

Paso 7

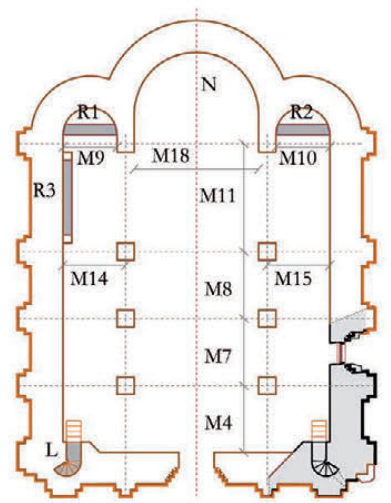

Reconstrucción hipotética de la planta de la iglesia románica de Samos en el siglo XIII
A: espacio interior de la iglesia románica B: espacio del claustro coetáneo

C: portada románica, punto de comunicación entre el interior del templo y el claustro

M1 =1'80 m (Medida extrapolable al resto de muros de la iglesia románica)

D: contrafuerte

D1: eje del contrafuerte D

E: torre

M3 $=320 \mathrm{~m}$

M4 $=3$ ' $80 \mathrm{~m}$ (Dimensión del último tramo de las naves)

M5 $=1,80 \mathrm{~m}$ (Fachada)

F: restos del contrafuerte derecho

F1: eje del contrafuerte $\mathrm{F}$

C1: eje de simetría de la portada románica

M6 = Dimensiones y planta del primer contrafuerte (D) con valores extrapolables al resto de contrafuertes existentes M7 $=3$ ' $81 \mathrm{~m}$ (Dimensión del segundo tramo de las naves) 3

G: contrafuerte

G1: eje del contrafuerte $G$

H: consideración de igualdad de dimensión entre tramos por analogía tipológica

M8 = 3'81 m (Dimensión del primer tramo de las naves) $\quad 4$

R: Los tres retablos representados son piezas diseñadas por el escultor Francisco de Moure para la iglesia románica en e siglo XVII. En la actualidad se encuentran reubicados en la iglesia nueva, y la medida de su ancho nos aporta tres dimensiones clave de la iglesia desaparecida: el ancho de sus dos naves laterales y de su crucero.

R1: Retablo de la Virgen, en la capilla lateral del mismo nombre

R2: Retablo de San Benito, en la capilla lateral del mismo

nombre

R3: Retablo de Santa Gertrudis en el extremo norte del crucero

M9 $=$ M10 $=3^{\prime} 22 \mathrm{~m}$ (Dimensión de la anchura de los retablos de la Virgen y San Benito)

M11 = Dimensión del transepto o crucero

M12 $=4^{\prime} 24 \mathrm{~m}$ (Dimensión de la anchura del retablo de Santa

M12 $=424 \mathrm{~m}$ (Dimito

M13 = 5'16 m (Dimensión hipotética del retablo de Santa

Gertrudis construido en el siglo XVII)

M14 = Dimensión de la nave lateral del Evangelio

M15 = Dimensión de la nave lateral de la Epistola M14 $=$ M15

contorno de la bóveda de crucería (I) espacio del último tramo de la nave central

I: Planta de la bóveda de crucería situada sobre el último tramo de la iglesia actual

$\mathrm{M} 16=5^{\prime} 67 \mathrm{~m}>\mathrm{M} 4$

M17 $=9185 \mathrm{~m}$

planta de la capilla mayor reconstruida según el contrato de 1601

$\mathrm{J}$ : Capilla mayor románica original

K: Capilla mayor reconstruida según el contrato de 1601

M18 $=7^{\prime} 08 \mathrm{~m}$ o 22 pies carolingios (Dimensión de la anchura interior de la capilla mayor y por extensión de la nave central)

M19 = 9'98 m o 31 pies carolingios (Dimensión del largo de la capilla mayor reconstruida scgún cl contrato de 1601) M20 $=1^{\prime} 77 \mathrm{~m}$ o 5' 5 pies carolingios (Dimensión del grueso de la capilla mayor reconstruida según el contrato de 1601) 7

L: Escalera situada en la torre norte del templo nuevo, a donde fue trasladada desde la iglesia románica

$\mathrm{N}$ : Eje de simetría

- elemento románico original conservado (en planta) elemento románico original conservado (en sección) reconstrucción hipotética (en planta) reconstrucción hipotética (en sección) elemento correspondiente a una época posterior a la del templo románico original (en sección) esquinal conscrvado de la iglesia románica

piezas conservadas de la antigua iglesia de Samos, reutilizadas en el nuevo templo $012345 \mathrm{~m} O$

Figura 24. Proceso de restitución de la planta hipotética de la iglesia románica del monasterio de San Julián de Samos a partir de distintas fuentes: restos reales conservados y documentos escritos (Planos elaborados por la autora) 

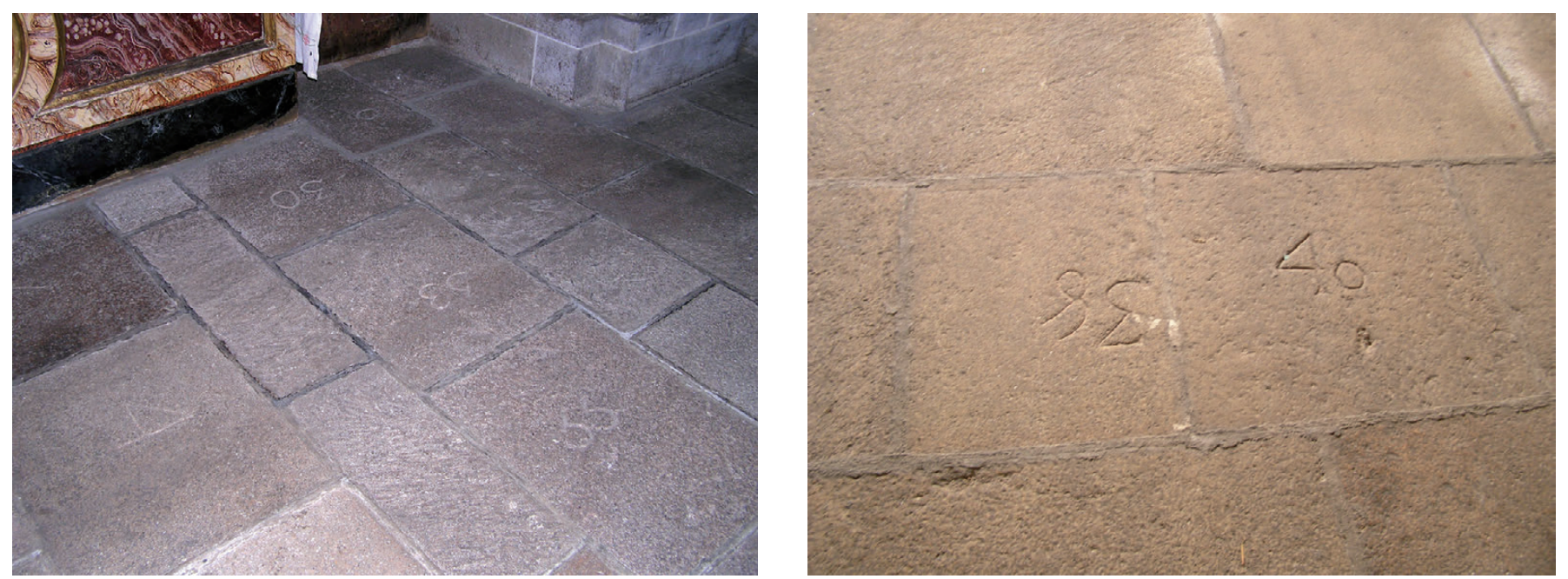

Figuras 25 y 26 . Algunas losas de piedra numeradas formando el pavimento de la iglesia de Samos actual (Fotografías de la autora)

tenga cinco pies y medio de gruesso y veinte y hocho pies de alto"36.

La obra se aplazó en el tiempo, firmándose un nuevo contrato el 14 de febrero de 1606 con los mismos canteros, bajo el periodo de gobierno del abad Francisco del Castillo. En este documento quedan recogidas las dimensiones que, al principio, querían que tuviese el nuevo ábside, así como la intención de ampliar la traza inicial para que "en altura y hueco y anchura de la ducha capilla mayor se ensanche, alargue y alze el arco de la dicha capilla corresponda con el arco del coro" 37 . Cuando hablan del "arco del coro", entendemos que se están refiriendo al arco exterior de la bóveda que soportaba el coro alto situado a los pies de la iglesia medieval, y que como ya hemos dicho, habría sido construido pocos años antes, a finales del siglo XVI.

A través de este contrato conocemos que las dimensiones que en un primer momento querían que tuviese la nueva cabecera eran de 22 pies de ancho, 31 de largo, 5 '5 de grueso y 28 alto, que haciendo la correspondencia de pies carolingios a metros lineales, serían 7’08 m de ancho, 9'98 de largo, 1'77 de grueso y 9 de alto ${ }^{38}$. Evidentemente el espacio de la nueva capilla mayor poco podía diferir de la original románica en cuanto a su anchura, la cual estaba delimitada lateralmente por

\footnotetext{
${ }^{36}$ Contrato entre el monasterio de Samos y los canteros Juan González y Alonso Rodríguez para que construyan la capilla mayor de la iglesia abacial, por un importe que será determinado por el sistema de tasación ajena. Archivo Histórico Nacional (AHN). Fondo Instituciones Eclesiásticas, Sección Clero secular-regular, Legajo 3452, folios 16-17. Este documento ha sido transcrito de forma íntegra en Folgar de la Calle y Goy, 2008, Apéndice documental [CD-ROM].

37 Ibidem.

${ }^{38}$ Para hacer la equivalencia ver nota 26.
}

el espacio ocupado por las capillas menores contiguas, aunque sí podían variar las medidas de su profundidad, el grosor de sus muros y la altura. De lo anterior podemos concluir que el ancho de la nueva capilla mayor, era el mismo que el de la existente, 7'08 m, y esta era también la dimensión que tenía en anchura la nave central correspondiente.

Del templo románico también se conserva un fragmento de una línea de imposta de la iglesia medieval, con una decoración en forma de ajedrezado o molduras de "billetes", que son adornos a modo de pequeños tacos cilíndricos que se colocaban a tresbolillo ${ }^{39}$. Este tipo de solución decorativa fue muy utilizada en el románico gallego, para resolver las líneas de imposta tanto del exterior como del interior de los templos, y podemos encontrar ejemplos de este tipo de ornamento en los modelos tipológicos estudiados. Este último elemento que hemos citado no nos ofrece una información dimensional, pero sí estilística. De igual modo, en el interior del monasterio se guardan hoy en día otras piezas sueltas como algún capitel y un sarcófago ${ }^{40}$.

En la iglesia actual se conservan más elementos del templo románico. Entre ellos destaca la presencia de la escalera de caracol de la segunda torre desaparecida, que se trasladó al interior de torre norte nueva.

Asimismo creemos que las losas de piedra que conforman el pavimento de la iglesia actual en algunas zonas de las naves laterales (Figs. 25 y 26), pertenecieron en el pasado a la iglesia románica. Aún se puede ver en algunos casos la huella de su primitiva función, por

\footnotetext{
39 Rodríguez González, 2008, p. 49.

${ }^{40}$ Ver nota 8.
} 

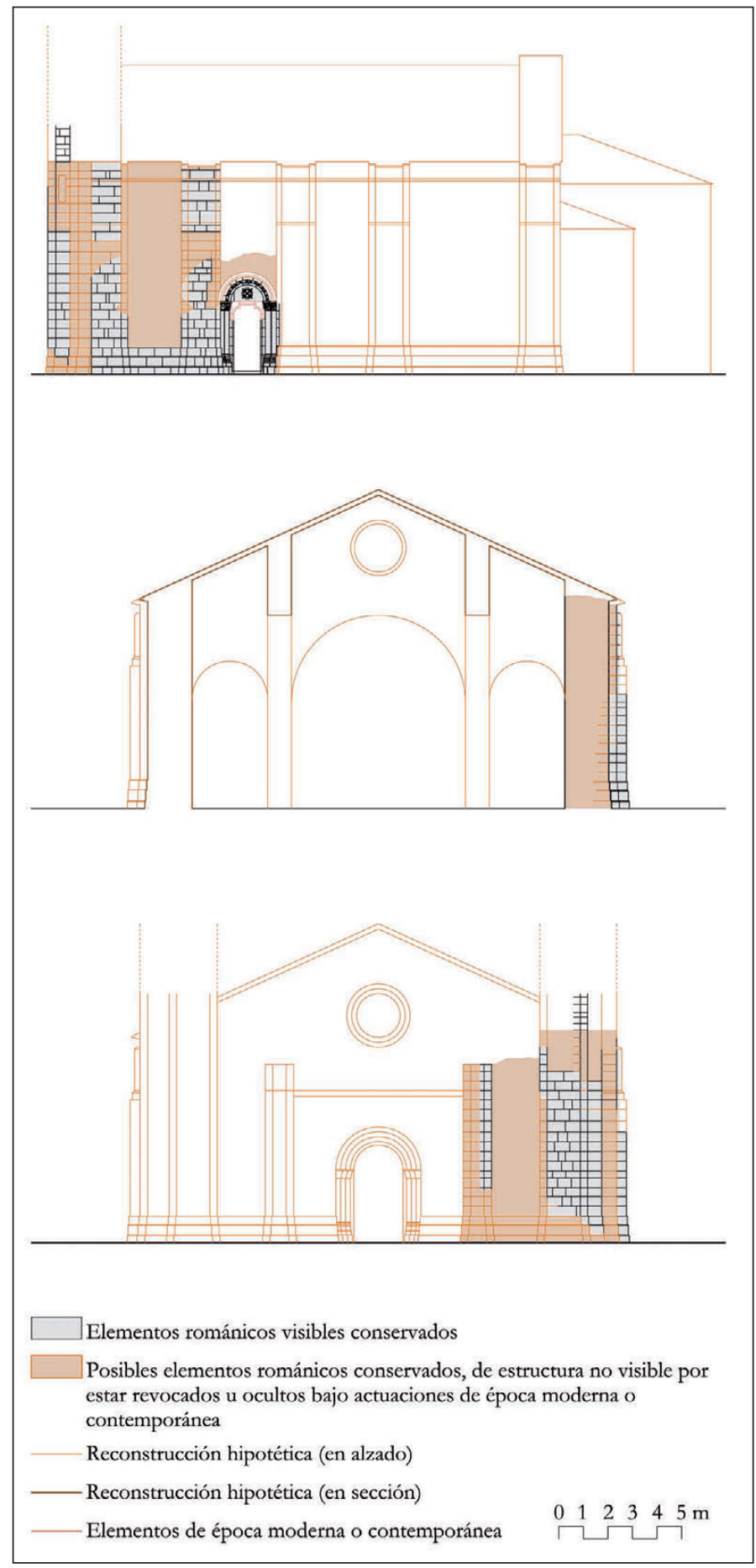

Figura 27. De arriba a abajo, reconstrucción hipotética del alzado sur, la sección por el último tramo de las naves y la fachada principal de la iglesia románica de Samos en el siglo XIII, a partir del esquinal conservado, de las dimensiones aportadas por documentos escritos y de la observación de otras iglesias de monasterios benedictinos (Planos de la autora)

las marcas centrales de antiguas argollas que permitían elevar las piezas; así como por las numeraciones talladas en ellas, de traza muy similar a la de las marcas de los maestros canteros localizadas en los sillares del esquinal sur conservado. La mayoría de estas losas trasladadas se concentran delante de los retablos de la Virgen, de San Benito y de Santa Gertrudis. Coincidencia que entendemos que no es casual, pues el suelo del templo románico era un lugar de sepultura, en el que las personas con más recursos se enterraban en la zona del crucero, a la cual miraban los tres retablos citados.

\section{RESULTADO Y CONCLUSIONES}

A modo de conclusión queremos hacer una reflexión acerca del proceso presentado en este artículo y de los resultados obtenidos.

Para empezar, es necesario recordar que el estudio que aquí mostramos forma parte de un trabajo de investigación mayor, que pretende, entre otros objetivos, el conocimiento completo del proceso de evolución de la fábrica actual del monasterio de San Julián de Samos, declarado monumento nacional histórico-artístico en Septiembre de 1944. Por tanto, no estamos ante un estudio aislado, sino que constituye uno de los eslabones de la cadena del proceso creativo de una arquitectura monacal con casi quince siglos de existencia.

La iglesia construida en Samos aproximadamente entre 1167 y 1228, permaneció en pie hasta 1746, fecha de su demolición para poder terminar la construcción del último tramo del actual templo monacal. Durante sus seis siglos de vida experimentó importantes cambios, responsables de la modificación de su imagen inicial, con el objetivo de adaptar el lugar de culto a las necesidades que tenía la comunidad en cada época. En el presente artículo nos centramos en el estudio del aspecto de la iglesia original, aunque también hemos tenido la necesidad de hacer referencia a las transformaciones sufridas en siglos posteriores, y que afectaron principalmente a su fachada, a la cabecera y al espacio interior.

La recopilación de datos de muy distinto origen -de documentos escritos y de piezas reales conservadas- y su lectura con el punto de vista adecuado al objetivo planteado, nos ha permitido recrear con solidez la planta de la iglesia románica de Samos en el siglo XIII. Creemos que la mayor aportación de nuestro trabajo radica en la elaboración de un método de restitución del aspecto de una arquitectura desaparecida a través de una triple aproximación, documental, tipológica y dimensional, que puede aplicarse al conocimiento de otros bienes patrimoniales, desaparecidos por causa de procesos derivados de la demolición o simplemente como consecuencia de transformaciones, abandono o ruina. 
Aunque nuestra propuesta dibujada es hipotética, lo estudiado hasta aquí consideramos que aporta la suficiente seguridad para decir que nuestra hipótesis planimétrica no debió ser muy diferente de la arquitectura real desaparecida. Una excavación arqueológica en el terreno ajardinado que configura el espacio del actual claustro del P. Feijoo, podría sacar a luz parte de las cimentaciones del antiguo templo y confirmar o rebatir nuestros planteamientos.

\section{AGRADECI MI ENTOS}

Este texto constituye parte de un capítulo de la Tesis Doctoral que estamos desarrollando bajo la dirección de José Ramón Soraluce Blond, en la que abordamos el estudio e interpretación del diseño y la evolución de una arquitectura monástica, San Julián de Samos, en la provincia de Lugo. Nuestra investigación ha sido parcialmente financiada por la Universidad de A Coruña (Ref.: Ayuda de apoyo a la etapa predoctoral UDC 2011) y actualmente por la Xunta de Galicia (Ref.: Ayuda de apoyo a la etapa predoctoral del Plan Gallego de Investigación, Innovación y Crecimiento 2011-2015 - Plan IC2), cofinanciado por el Fondo Social Europeo (FSE-FEDER). La autora quiere agradecer a la comunidad benedictina de San Julián de Samos su interés y su permanente predisposición para facilitar nuestra investigación, sin lo cual no sería posible el desarrollo de este trabajo.

\section{Bibliografía}

Arias Cuenllas, M., 1968: Un abadologio inédito del Monasterio de Samos. Real Abadía de Samos, Samos.

Arias Cuenllas, M., 1981: "El monasterio de Samos desde sus orígenes hasta el siglo XI”, Archivos Leoneses, 70, pp. 267-350.

Arias Cuenllas, M., 1983: "El monasterio de Samos durante los siglos XI y XII”, Archivos Leoneses, 73, pp. 7-82.

Arias Cuenllas, M., 1992: Historia del monasterio de San Julián de Samos. Monasterio de Samos, Samos.

Bango Torviso, I. G., 2003: "La iglesia monástica en la España Medieval (500-1200)”, en Monasterios románicos y producción artística, pp. 215229. Fundación Santa María La Real, Aguilar de Campoo.

Castro, M., 1912: “Un monasterio gallego”, Boletín de la Comisión Provincial de Monumentos Históricos y Artísticos de Orense, IV, 82, pp. 113-120; 83, pp. 136-143; 84, pp. 163-171; y 85, pp. 189-195.

De la Portilla Costa, P., 1978: Monasterio de Samos. Guía histórico-artística. Colección Temas Lugueses, Monasterio de Samos. Lugo.
De la Portilla Costa, P., 1984: El monasterio de Samos. Editorial Everest, Madrid.

De la Portilla Costa, P., 1988: “San Julián de Samos”, en Monasterios de España, pp. 25-88. Editorial Everest, Madrid.

De la Portilla Costa, P., 2001: "El desaparecido retablo mayor de la antigua iglesia románica del Monasterio de S. Julián de Samos: Estudio iconográfico", en Miscelánea samonense: homenaje al P. Maximino Arias O.S.B, pp. 145-163. Diputación Provincial de Lugo, Lugo.

Del Castillo, Á., 2008: Inventario de la riqueza monumental y artística de Galicia. Fundación Pedro Barrié de la Maza, A Coruña.

Durán, M., 1947: La Real Abadía de San Julián de Samos: estudio históricoarqueológico. Madrid.

Folgar de la Calle, M. C., 2006: “A construcción do gran mosteiro de San Xulián de Samos. Cen anos de transformacións arquitectónicas”, en Arte benedictina nos camiños de Santiago. Opus Monasticorum II, pp. 211-230. Xunta de Galicia, Santiago de Compostela.

Folgar de la Calle, M. C., 2008: “Iter operis ou a relación sobre a definición da fábrica do mosteiro samonense: a construcción da nova igrexa e dun novo claustro", en San Xulián de Samos: Historia e arte nun mosteiro, Opus Monasticorum III, pp. 149-178. Xunta de Galicia, Santiago de Compostela.

Folgar de la Calle, M. C. y Goy Diz, A. (dir.), 2008: San Xulián de Samos: Historia e arte nun mosteiro, Opus Monasticorum III. Xunta de Galicia, Santiago de Compostela.

Franco Taboada, J. A. (coord.), 2001: Mosteiros e conventos de Galicia. Xunta de Galicia, Santiago de Compostela.

López Calderón, M., 2008: “A obra do ‘escultor e arquitecto’ Francisco de Moure en San Xulián de Samos”, en San Xulián de Samos: Historia e arte nun mosteiro, Opus Monasticorum III, pp. 193-208. Xunta de Galicia, Santiago de Compostela.

Lucas Álvarez, M., 1986: El tumbo de san Julián de Samos (siglos VIII-XII). Estudio introductorio. Edición diplomática. Apéndices e índices. Caixa Galicia, Santiago de Compostela.

Mannoni, T., 1998: "Analisi archeologiche degli edifici con structture portanti non visibili”, Archeologia dell'Architetture, 3, pp. 81-85.

Merino de Cáceres, J. M., 2000: Metrología y composición en las catedrales españolas. Papeles de arquitectura española 3, Fundación Cultural Santa Teresa \& Instituto de Arquitectura Juan de Herrera, Ávila.

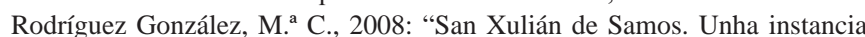
de poder na Idade Media”, en San Xulián de Samos: Historia e arte nun mosteiro, Opus Monasticorum III, pp. 49-72. Xunta de Galicia, Santiago de Compostela.

Utrero Agudo, M. Á., 2010: “Archeology. Archeologia. Arqueología. Hacia el Análisis de la Arquitectura”, en Arqueología aplicada al estudio e interpretación de los edificios históricos. Últimas tendencias metodológicas, pp. 11-23. Ministerio de Cultura, Madrid.

Valle Pérez, J. C., 2001: "La expansión de la arquitectura románica en Galicia: tipologías, fuentes y desarrollo”, en El Arte Románico en Galicia y Portugal, pp. 113-126. Fundación Pedro Barrié de la Maza/Fundação Calauste Gulbenkian, A Coruña.

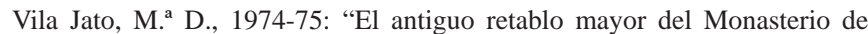
San Julián de Samos (Lugo)”, Cuadernos de Estudios Gallegos, XXIX, pp. 141-146.

Yzquierdo Perrín, R., 2001: "El arte medieval en el arciprestazgo de Samos”, en Miscelánea samonense: homenaje al P. Maximino Arias O.S.B, pp. 5371. Diputación Provincial de Lugo, Lugo. 